\title{
Interactive Combustion in a Linear Array of 2D Laminar Isolated and Triple Burner Jets
}

\author{
S. T. Tillman, ${ }^{1}$ S. Kuchibhatla, ${ }^{2}$ K. Annamalai, ${ }^{2}$ J. A. Caton, ${ }^{2}$ and D. Ranjann ${ }^{2}$ \\ ${ }^{1}$ Systems Development \& Deployment, Information Systems, 6767 Old Madison Pike, Suite 160, Huntsville, AL 35806, USA \\ ${ }^{2}$ Department of Mechanical Engineering, Texas A\&M University, College Station, TX 77843, USA
}

Correspondence should be addressed to D. Ranjan, dranjan@tamu.edu

Received 6 January 2012; Revised 27 May 2012; Accepted 6 June 2012

Academic Editor: Suk Ho Chung

Copyright ( $\odot 2012$ S. T. Tillman et al. This is an open access article distributed under the Creative Commons Attribution License, which permits unrestricted use, distribution, and reproduction in any medium, provided the original work is properly cited.

\begin{abstract}
Many practical combustion systems such as residential gas burners contain dense groupings or clusters of jet flames with sufficiently small spacing between them, which causes flame interaction. The interaction effect, due in part to Oxygen deficiency in the interstitial space between the flames, causes the spreading of flames, which may merge together to form larger group flames. This interactive effect is studied analytically by revisiting the laminar isolated flame theory for 2D jets, for which similarity solutions are readily available in compressible form, and symmetrical interaction zones can be observed. Flame characteristics were studied by obtaining analytical expressions for flame specific parameters such as height and width, lift-off height and blow-off velocity, air entrainment and mixing layer growth. The theory for multiple interacting jets describes an approximate criterion for interburner spacing at which flame interaction and group flame formation are first observed. The analytical framework presented in this paper presented in this paper produced results which were compared with experimental measurements. The experimental apparatus allowed the interburner spacing to be varied from $7.87 \mathrm{~mm}$ to $50.8 \mathrm{~mm}$, and measurements of flame height, width, lift-off height and group-flame formation under interactive modes. Images of the evolving flow field were taken and Schlieren images of the multiple $2 \mathrm{D}$ jets were also recorded using a digital camera.
\end{abstract}

\section{Introduction}

In order to study the stability and combustion behavior of interacting jet diffusion flames, laminar single flame stability theory must be developed for a burner and extended to include the effect of multiple burners. In this current work, a stability theory for jets is introduced and the appropriate generalized conservation equations for momentum, species, and energy for $2 \mathrm{D}$ compressible systems with boundary conditions are presented. The governing equations are solved to give explicit solutions for axial and radial gas velocities, flame height, maximum flame width and its axial location, amount of air entrainment, lift-off height and blow-off velocity as a function of injection Reynolds number (Re), Schmidt number $(S c)$, and fuel composition. We begin by summarizing relevant literature review corresponding to single-flame combustion. Literature regarding the stability characteristics (lift-off height and blow-off velocity) of single jet diffusion flames is quite extensive.
Some of the relevant endeavors are summarized here. Van quickenborne and Van Tiggelen [1] studied the stabilization of lifted, turbulent, diffusion flames and measured the gas composition, gas flow velocity, intensity, and Eulerian scale of turbulence for a free jet of Methane issuing from circular burners with inner diameters of $1.33 \mathrm{~mm}, 1.8 \mathrm{~mm}$, and $2.4 \mathrm{~mm}$. In particular, they found that the base of the lifted flame anchors in a region corresponding to the formation of a stoichiometric mixture, where, turbulent burning velocity equals the flow velocity. They also noted that blow-off in jet diffusion flames is not an extinction phenomenon since the flame can be maintained at various heights, provided a permanent ignition source. Kalghatgi [2] theorized that the blow-off velocity is a function of the laminar flame speed and height of the stoichiometric contour and found via experimentation a "universal" nondimensional formula to describe the blow-out stability limit of gaseous jet diffusion flames in still air. Chung and Lee [3] experimentally studied the characteristics of laminar lifted 


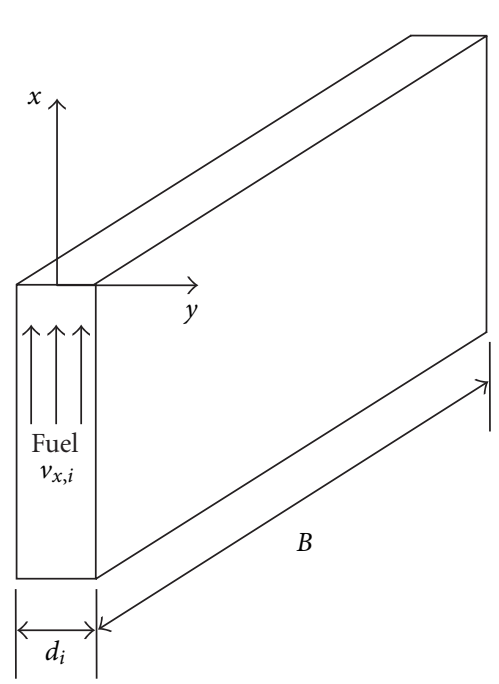

(a) 2D jet geometry $\left(d_{i}<<B\right)$

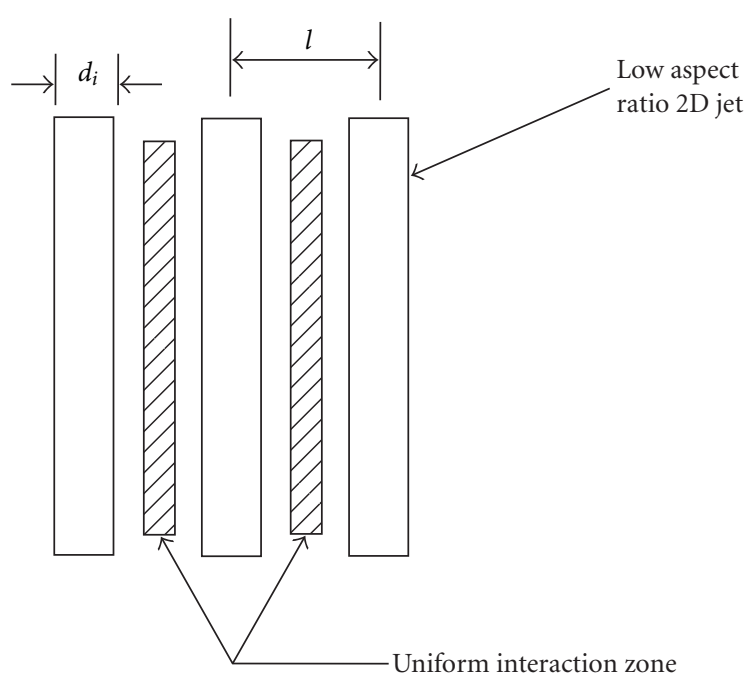

(b) Top view of a linear array of $2 \mathrm{D}$ jets spaced at a distance $l$

FIGURE 1: Burner configurations.

flames stabilized in a nonpremixed jet. The jet was released from nozzles made of Quartz tubing, with inner diameters of $0.164,0.195$, and $0.247 \mathrm{~mm}$ at the nozzle exit. They found that the stabilization mechanisms of lifted flames could be interpreted using laminar cold theory based on the premise that the lift-off height is much greater than the preheat zone. Based on this assumption, they derived an expression for liftoff height as a function of the flow rate, burner diameter and $S c$. They also correctly identified $S c$ as a key player in the stability mechanism for circular jets, noting that the lift-off height will increase with an increase in flow-rate for $S c<0.5$ and $S c>1$ but will decrease for $0.5<S c<1$.

The above studies focused on circular burners. However, $2 \mathrm{D}$ jets where $\left(d_{i} \ll B\right.$ as shown in Figure $\left.1(\mathrm{a})\right)$ are more suitable for interaction studies since the radius of influence around a central jet can be made uniform (Figure 1(b)). As shown in the figure, at a given height above the burner, the interaction zone will be uniform, meaning that two burners placed on either side of the central flame will be the only influences (end effects can be neglected since $d_{i} \ll B$ ). Given their physical considerations, it is believed that a more accurate study of interactive processes can be conducted with 2D burners. An added advantage to analytically studying 2D burners is that variable transformation is available allowing similarity solutions for the compressible form of the governing equations. Similarity solutions for circular jets are feasible under the assumption of incompressibility, which is clearly invalid for combustion processes. From the above discussion, a general idea of literature on single-flame theory and experiments can be inferred. Extending the discussion to multiple flame interaction is presented in the next few paragraphs.

In light of the numerous practical applications of multiple burner arrays in industry and elsewhere, fundamental information regarding the factors governing flame interaction is required. The separation distance between individual burners in many combustion systems is often small enough to cause the flames to interact with one another resulting in a change of flame structure (such as greater flame length and width) and a change in stability characteristics of the flame (such as higher blow-off velocity). Multiple flame interaction also exhibits reduced $\mathrm{NO}_{\mathrm{x}}$ production [4] under certain conditions. As such, one of the main objectives of combustor design is to maximize flame stability while simultaneously minimizing thermal $\mathrm{NO}_{\mathrm{x}}$ production. Towards this objective, cluster burners, wherein multiple flames (more than 94 swirl burners in a typical combustor) are being investigated in the gas turbine industry. Several important factors which may influence the interactive process are (a) number of burners, (b) spacing between the burners, (c) fuel flow rate through the burners, (d) properties of the fuel, (e) array geometry (such as linear, square, triangle arrangement, etc.), and (f) exit plane geometry of the burners (circular, planar, elliptical, etc.). Flame interaction, therefore, is believed to a complicated phenomenon. In order to keep the physics in tractable form, this study will concentrate only on a linear array of three laminar 2D burners fired with gaseous fuels.

Whereas literature regarding isolated jet flames is quite extensive (as discussed earlier), literature regarding stability characteristics of interacting multiple flames is scarce. One of the earliest studies of multiple flames was conducted by Putnam and Speich [5] who presented a model for studying mass fires using buoyancy controlled, turbulent, multiple jets of gaseous fuels. Each jet was represented as a point source and the important parameters which govern the interactive process were identified to be (a) multipleflame height to single-flame height ratio, (b) number of jets, (c) source-shape factor, and (d) flame spacing to fuelflow rate ratio. They also observed that in some cases of specific flowrates and array geometries, the single flames merged to form larger flames. Lenze et al. [6] measured the axial concentrations of $\mathrm{H}_{2}$ and $\mathrm{CO}$ for an array of three and five turbulent circular burners fired with both town gas and natural gas. They observed a relation between 
the visible flame heights in multiple jet arrangements and the axial location where $\mathrm{CO}$ concentration approached zero. In addition, they observed a simple relationship between the increase in height of turbulent interacting flames to the height of a single, turbulent isolated flame. However, their studies were limited to an attached turbulent flame issuing from circular burners and made no attempt to fundamentally understand the flame stability processes under interactive modes. A more comprehensive study of the interactive process was conducted by Menon and Gollahalli [7]. They measured visible flame height, merging length, blow-off velocity, temperature profiles, and concentration levels of $\mathrm{O}_{2}, \mathrm{CO}$, and $\mathrm{NO}$ as a function of separation distance for lifted flames issuing from circular jets fired with Propane (inner jet diameters of $1,2,3,3.5$, and $5 \mathrm{~mm}$ ). They found that the interaction of multiple jets increased the flame length, increased the blow off velocity, decreased the peak temperature levels, increased the CO levels and decreased the NO levels. However, the study was limited to circular burners which are not ideal for interactive studies as previously mentioned.

\section{Objectives and Outline}

The primary objective of the current work is to describe the physics of the interactive processes between multiple $2 \mathrm{D}$ jets. Particular interest will be paid to the dependence of flame geometry (flame height, flame width, mixing layer growth, etc.) and stability characteristics (lift-off height and blowoff velocity) on interburner spacing, $R e$ and fuel composition. By obtaining similarity solutions for the governing equations for a single 2D jet in compressible form, analytical expressions for flame height and width, lift-off height and blow-off velocity, air entrainment, and mixing layer growth as a function of injection $R e$ and fuel composition can be obtained. A discussion on the importance of the $S c$ on the lift-off height calculations will be attempted. By expanding single flame theory to include multiple burner effects, one can gain an insight into the various mechanisms of interaction between individual flames. Comparisons between theoretical predictions and experimental measurements of flame height, maximum flame width, lift-off height, blowoff velocity (for single burner), and interburner spacing (where group flames are formed) will be given. Overall, this paper aims to understand the physics of multiple flames, provide approximate analytical solutions for basic burner configurations, and validate those using experimental data. This valuable knowledge can aid in the development of a theory for turbulent multiple flames and even optimization of burner configurations for specific applications.

Therefore, the current work is organized to present analytical models for isolated and multiple burner jets followed by experimental results for comparison with the models. A review of the conservation equations for an isolated 2D jet in compressible form, a presentation of flame stability theory in Section 3, and a summary of the relevant results in tabular form for an isolated 2D jet are presented in Section 4 . Thereafter, theory for single burners is extended to multiple 2D jets (with few approximations) in Section 5 . A criterion for predicting the interburner spacing at which (i) flame interaction and (ii) group flame formation begin is also presented, and modes of interaction for a linear array of $2 \mathrm{D}$ jets are identified. In order to validate the analytical expressions obtained from the isolated flame theory, a simple apparatus consisting of an enclosed isolated 2D jet was constructed. Experimentally measured data on flame height, maximum flame width and its axial location, lift-off height, and blow-off velocity for the isolated jet is then presented for comparison in Section 6. Thereafter, the experimental apparatus was modified to include three, side-by-side $2 \mathrm{D}$ jets of orifice size $0.8 \mathrm{~mm} \times 6.35 \mathrm{~mm}$. Details of the experimental apparatus and results are presented in the following Section 7 for multiple burner jets. Measurements of flame height, blow-off velocity, and group-flame formation under interactive modes, using a digital camera are presented. Schlieren images of the multiple 2D jets are also provided. Another set of experimental data corresponding to multiple jets is then presented for comparison with the analytical results. Conclusions drawn from both analytical and experimental studies are given in Section 8.

\section{Analytical Model Formulation for Single Flame}

3.1. Flame Stabilization in $2 D$ Jet. For the pure mixing problem, the axial velocity $v_{x}$, fuel and oxygen mass fraction profiles $\left(Y_{F}, Y_{\mathrm{O}_{2}}\right)$ are qualitatively shown in Figure 2(a). Since the fuel mass fraction at the center of the jet is high and the fuel mass fraction in the far field is low, the mixture is only ignitable within a narrow range where the fuel and air are in combustible proportions. Here $H$ is the flame height. An expanded view of this ignitable region is shown in Figure 2(b). For $y<y_{R}$, the mixture is too fuel rich to ignite and for $y>y_{L}$, the mixture is too lean to ignite. At some distance $y_{s t}$ the mixture will be in stoichiometric proportions. Given these restrictions on the flammability limits, if the mixture is ignited within the region bound by TRC (rich limit) and NFB (lean limit) as shown in Figure 2(b), the flame can propagate only within the narrow region $\delta$, which will be called the combustible mixture tube. It is important to emphasize that the flame propagation for the fuel fired laminar jet is very different from the flame propagation for the premixed Bunsen burner flame. For this work, it was assumed that the combustible mixture tube was thin and could be represented by the position in space where the fuel and air are in exact stoichiometric proportions (dashed line MGKD in Figure 2(b)). Given this discussion, the flame stability characteristics of the single 2D jet can be mapped by analyzing two contours: (a) the stoichiometric contour representing the stoichiometric or combustible mixture tube where $Y_{\mathrm{O}_{2}} / Y_{F}=\nu_{\mathrm{O}_{2}}$ and (b) the flame speed contour representing the positions in space where the axial velocity is equal to the flame speed $\left(v_{x}=S\right)$.

Four possible scenarios exist as shown in Figure 3. First, the stoichiometric contour can lie "inside" the flame speed contour (Figure 3(a)). Secondly, the stoichiometric contour 


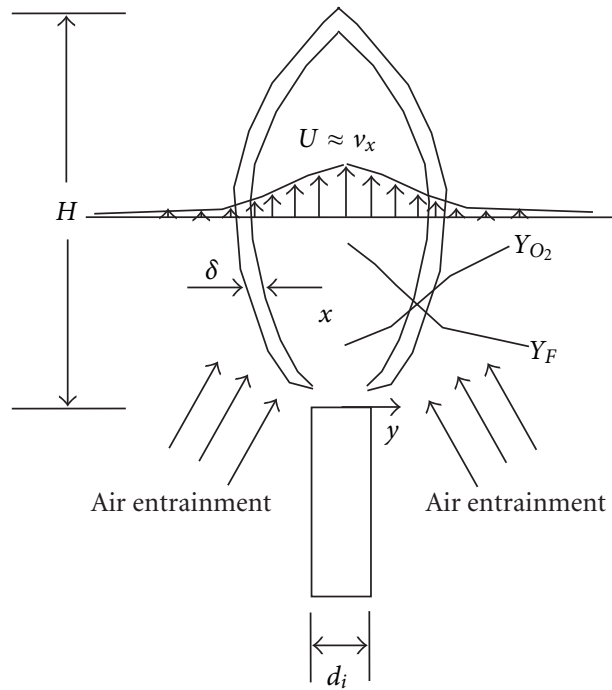

(a) Profiles of axial velocity, fuel, and oxygen mass fraction for a $2 \mathrm{D}$ jet under mixing conditions. A qualitative illustration of the mass fraction of oxygen and fuel is shown

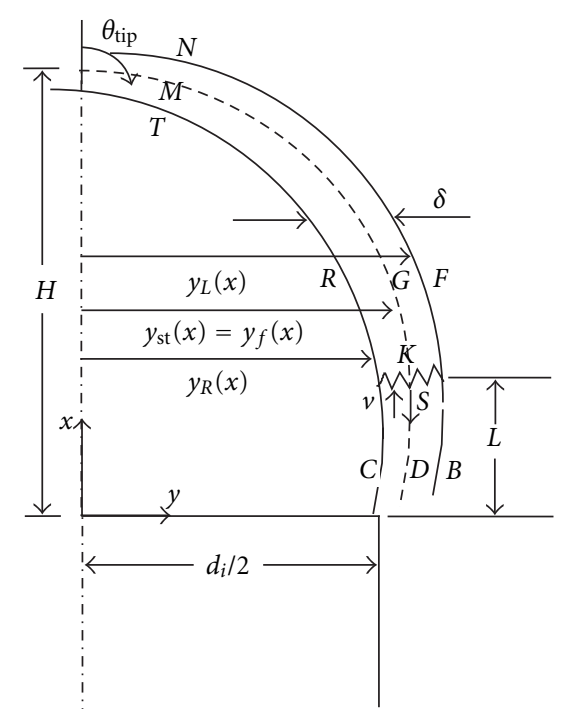

(b) Expanded view of the combustible mixture tube

FIGURe 2: Profiles describing various aspects of the flame.

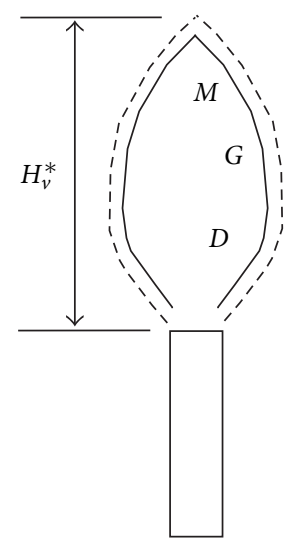

(a) Unstable flame $S c \approx 1$

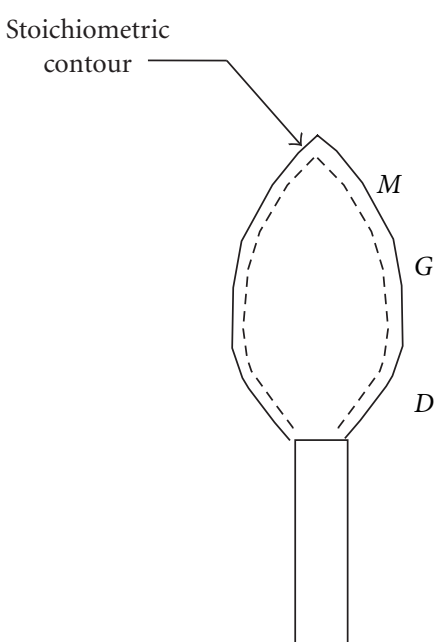

(b) Nozzle attached flame

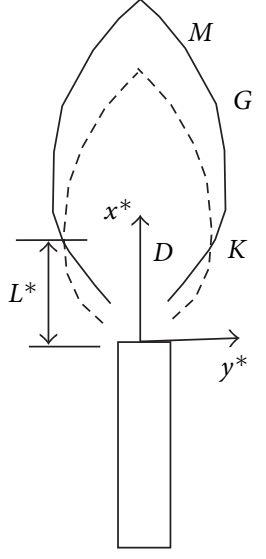

(c) Lifted flame $S c>1$

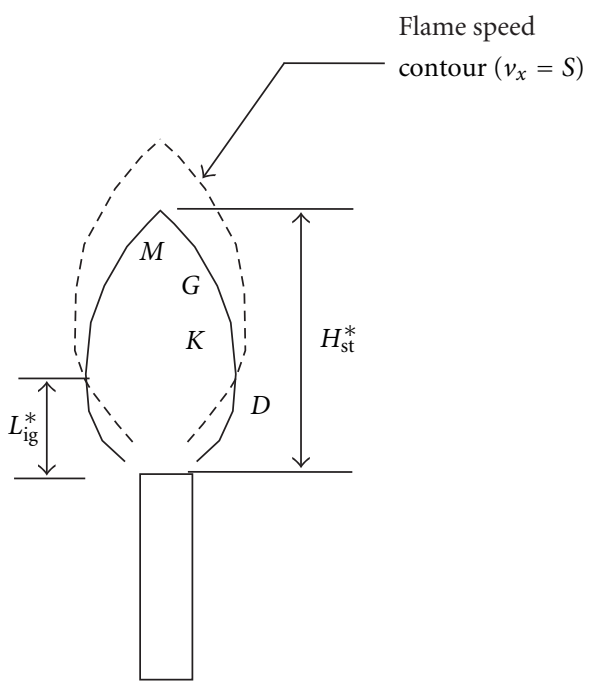

(d) Partial flame $S c<1$

FIGURE 3: Qualitative illustrations of stoichiometric (solid) and flame speed (dashed) contours; $H^{*}$ (nondimensional height).

can lie "outside" the flame speed contour (Figure 3(b)). Thirdly and fourthly, the contours can intersect at some distance away from the burner (Figures 3(c) and 3(d)). Consider the first option (Figure 3(a)). If the stoichiometric contour lays "inside" the flame speed contour, then at every point along the stoichiometric contour (line MGD in Figure 3(a)) the axial gas velocity will be higher than the flame speed (since momentum diffuses in the radial direction). If an ignition source were provided at $M$, the flame would attempt to propagate along the stoichiometric contour towards the burner at a velocity equal to the laminar flame speed $S$.
But the axial gas velocity is higher than the flame speed $\left(v_{x}>S\right)$ along the stoichiometric contour and therefore, the flame moves away downstream from the burner. As it moves downstream, the axial gas velocity decreases but is still higher than the flame speed (the condition for finding an anchoring position). However, this must happens beyond the tip of the stoichiometric contour where the mixture is no longer combustible. Given this discussion, the first option will result in blow-off. Consider the second possibility Figure 3(b)), where the stoichiometric contour lies "outside" the flame speed contour. In such a configuration, the magnitude of the axial 
gas velocity is less than the flame speed $\left(v_{x}<S\right)$ along the stoichiometric contour. If an ignition source were provided at $M$, the flame would propagate towards the burner since the axial gas velocity along the stoichiometric contour is now less than the flame speed $\left(v_{x}<S\right)$. This leads to a nozzle attached flame anchored at the burner base. The third possibility (Figure 3(c)) where the stoichiometric contour and the flame speed contour intersect gives the anchoring position for the flame ( $v_{x}=S$ and $Y_{\mathrm{O}_{2}} / Y_{F}=v_{\mathrm{O}_{2}}$ at the intersection point). Further downstream from the intersection point, the stoichiometric contour lies "outside" the flame speed contour which is a stable profile as shown in Figure 3(b). From the intersection point toward the burner base, the stoichiometric contour lies on the "inside" of the flame speed contour which is an unstable profile as shown in Figure 3(a). Therefore, the flame can only exist from the intersection point $K$ in Figure $3(\mathrm{c})$. to the tip of the stoichiometric contour. Hence, $L^{*}$ gives the lift-off height of the flame. Now consider the fourth possibility (Figure 3(d)): If an ignition source were provided at $M$, the flame would attempt to propagate at $S$. However, the axial gas velocity at $M$ is much higher than the flame velocity and hence the mixture cannot be ignited at $M$. If an ignition source were provided at $D$, the axial gas velocity would less than $S$ and as such the flame would propagates towards the burner base. The flame is therefore only ignitable up to position $K$ and hence, $L_{I}^{*}$ (limited ignition) gives the ignitable height from the burner rim. To summarize, the fuel mixture is not ignitable for $L_{I}^{*}<x<H^{*}$.

As will be explained in the upcoming discussion, Schmidt number plays a key role in defining the various possibilities shown in Figures 3(a) to 3(b). If $S c>1$, lifted flames are predicted (Figure 3(c)). If $S c<1$, partial flame or ignitable heights are predicted (Figure $3(\mathrm{~d})$ ). If $S c=1$, no intersection between the contours is possible and the predicted flames are either (i) stable and anchored at the burner base (Figure 3(b)) or (ii) blown off (Figure 3(a)). Explicit expressions for plotting the stoichiometric contour and the flame speed contours shown in Figures 3(a) to 3(d) can be found by solving the governing differential equations for the single $2 \mathrm{D}$ jet.

\section{Discussion of Single-Flame Analytical Model}

4.1. Summary of Solutions. For the isolated 2D jet, the equations of mass, momentum, energy, and species were transformed from compressible form into incompressible form (Annamalai and Sibulkin, [8]), normalized, converted into ordinary differential equation using an appropriate similarity variable, and solved with the appropriate boundary conditions to give solutions for the axial and radial velocity $\left(v_{x}\right.$ and $\left.v_{y}\right)$, the species concentrations ( $Y_{F}, Y_{\mathrm{O}_{2}}$, etc.), the flame height $(H)$, the lift-off height of the flame $(L)$, and the blow-off velocity $\left(v_{\text {blow }}\right)$. For the complete, step by step, details of the derivations for 2D jet and circular jets including the use of stretched variables in deriving incompressible forms of conservation equations, conversion to ordinary differential equation using similarity variables, solution of ordinary differential equation for velocity, species, and so forth refer to Annamalai et al. $[9,10]$. The solutions to the governing differential equations are summarized in tabular form in Table 1. For the sake of compactness, details of derivation are omitted. All solutions are presented in absence of buoyancy forces. If buoyancy forces are included, $M^{*}$ and $J^{*}$ will be larger than the values listed. In Table 1, rows 9, 10, and 16 summarize the solutions of axial velocity, lateral velocity, and species/temperature profiles for mixing problem or Shvab-Zeldovich variable profiles for combustion problems. For lift-off and blow-off analyses, the Shvab-Zeldovich formulation is unnecessary. However, for defining the criteria for interaction, solution to the Shvab-Zeldovich formulation is needed.

For variable density see Fay [12]. Details of the derivation and summary of results for circular jet can be found in Tillman [13].

4.2. Solution for Stoichiometric Contour. In order to determine the lift-off height and blow-off velocity of 2D jets, the mixing problem must be solved. By setting $b=Y_{F}$ and $Y_{\mathrm{O}_{2}}$ in the result for row 16 in Table 1, solutions for $Y_{F}\left(y^{*}, x^{*}\right)$ and $Y_{\mathrm{O}_{2}}\left(y^{*}, x^{*}\right)$ can be obtained. Using these results, the stoichiometric contour $y_{\mathrm{st}}^{*}\left(x^{*}\right)$ where

$$
Y_{F}=\frac{Y_{\mathrm{O}_{2}}}{v_{\mathrm{O}_{2}}}
$$

can be obtained and at any specified $x^{*}, y_{\text {st }}^{*}\left(x^{*}\right)$. If one uses Shvab-Zeldovich formulation for combustion problem under finite kinetics, then at stoichiometric surface $Y_{F} \neq 0$ and $Y_{\mathrm{O}_{2}} \neq 0$ but $\beta_{F-\mathrm{O}_{2}}=0$. At thin limit $Y_{F}=0$ and $Y_{\mathrm{O}_{2}}=$ 0 and still $\beta_{F-\mathrm{O}_{2}}=0$. Using the solution given in row 16 and (1), $y_{\mathrm{st}}^{*}\left(x^{*}\right)$ will be the same for these additional two cases. For the stoichiometric contour (or flame contour),

$$
\begin{aligned}
y_{\mathrm{st}}^{*}\left(x^{*}\right)=y_{f}\left(x^{*}\right)= & {\left[\frac{x^{* 2 / 3}}{0.2752 R e_{i}^{2 / 3} M^{* 2 / 3}}\right] } \\
& \times \cosh ^{-1}\left[\left(\frac{0.09375 C^{3} R e_{i} J^{* 3}}{M^{*} x^{*} \phi_{f}^{3}}\right)^{1 / 6 S c}\right],
\end{aligned}
$$

where $\phi_{f}$ is given by

$$
\phi_{f}=\frac{s}{(1+s)}
$$

where

$$
s=\frac{Y_{O_{2}, \infty}}{v_{O_{2}} Y_{F, i}}
$$

and $\nu_{\mathrm{O}_{2}}=$ stoichiometric ratio $\left(\nu_{\mathrm{O}_{2}}=4\right.$ for pure $\mathrm{CH}_{4}$ issuing into air). The flame profile in real coordinates will be exactly same as the stoichiometric contour only if properties remain constant for both mixing and combustion problems. Equations (3a) and (3b) can be rewritten as

$$
\begin{gathered}
\phi_{f}=\frac{1}{\left\{1+(A: F)_{\mathrm{st}}\right\}} \quad \text { for pure fuel with } Y_{F, i}=1, \\
\phi_{f}=\frac{1}{\left\{1+(A: I)_{\text {st }}\right\}} \quad \text { for } Y_{F, i}<1 .
\end{gathered}
$$


TABLE 1: Summary of single, laminar jet results for 2D planar jet under non-buoyant conditions.

\begin{tabular}{|c|c|c|c|}
\hline Row\# & Parameter & 2D Jet & Remarks \\
\hline 1 & Properties & Variable & $\begin{array}{l}\text { For } 2 \mathrm{D}, \rho^{2} D=\text { constant and } \\
\rho^{2} v=\text { constant. }\end{array}$ \\
\hline 2 & $M^{*}$ & $M^{*}=6 / 5$ for a parabolic $v_{x, i}$ profile & $\begin{array}{l}\text { forces important. } \\
M^{*}=M /\left(\rho_{i} v_{x, i} d_{i}^{2}\right) \text {, where } M \text { is the } \\
\text { axial momentum flux rate at the } \\
\text { inlet }\end{array}$ \\
\hline 3 & $J_{b}^{*}$ & $\begin{array}{l}J_{b}^{*}=6 / 5 \text { for a parabolic } v_{x, i} \text { and parabolic } b \\
\text { profile } \\
J_{b}^{*}=1 \text { for a parabolic } \nu_{x, i} \text { and flat } b \text { profile } \\
J_{b}^{*}=1 \text { for a flat } \nu_{x, i} \text { and flat } b \text { profile }\end{array}$ & $J_{b}^{*}=J_{b} /\left(\rho d_{i} v_{x, i}\left(b_{i}-b_{\infty}\right)\right)$ \\
\hline 4 & $\begin{array}{l}\text { Stretched coordinate } \\
\text { Similarity }\end{array}$ & $y^{\prime}=\int_{0}^{y}\left(\rho / \rho_{i}\right) d y$ & $\begin{array}{l}\text { For an ideal gas with a constant } \\
\text { molecular weight } \rho / \rho_{i}=T_{i} / T\end{array}$ \\
\hline 5 & Coordinate, $\eta[11]$ & $\begin{array}{l}\eta=M^{* 1 / 3}\left(y^{*} x^{* 2 / 3}\right)\left(R e_{i} / 3\right)^{2 / 3} \\
y^{*}=y^{\prime} / d_{i}\end{array}$ & \\
\hline 6 & $\begin{array}{l}\text { Modified Similarity } \\
\text { variable, } \xi\end{array}$ & $\begin{aligned} \xi & =(1 / 2) M^{* 1 / 3}(3 / 2)^{1 / 3} \eta \\
& =\left((1 / 2) M^{*}(3 / 2)^{1 / 3}\left(y^{*} / x^{* 2 / 3}\right)\left(R e_{i} / 3\right)^{2 / 3}\right. \\
& =0.2752 R e_{i}^{2 / 3} y^{*} M^{* 1 / 3} / x^{* 2 / 3}\end{aligned}$ & \\
\hline 7 & $\begin{array}{l}\text { Momentum equation } \\
\text { in } \eta \text { and other } \\
\text { solutions }\end{array}$ & $\begin{array}{l}f^{\prime 2}+f f^{\prime \prime}+f^{\prime \prime \prime}=0 \\
f^{\prime}=(1 / 2)(3 / 2)^{(2 / 3)} \operatorname{Sech}^{2} \xi \\
f=(3 / 2)^{1 / 3} \tanh \xi \\
v_{x}^{*}=f^{\prime}(\xi) M^{* 2 / 3}\left\{\operatorname{Re}_{i}\left(3 x^{*}\right)\right\}^{1 / 3} \\
v_{y}^{*}=\left[\left\{M^{*} \operatorname{Re}_{i}\right\}^{1 / 3}\left\{(3 x)^{* 2 / 3}\right\}\right]\left\{2 f^{\prime}(\xi)-f(\xi)\right\}\end{array}$ & \\
\hline 8 & Species equation in $\psi$ & $\begin{array}{l}\psi^{\prime \prime}+S c f^{\prime} \psi+S c f \psi^{\prime}=0 \\
\text { where } \psi=\varphi x^{* 1 / 3}\end{array}$ & \\
\hline 9 & $\begin{array}{l}\text { Axial velocity } \\
v_{x}^{*}=v_{x} / v_{x, i}\end{array}$ & $\begin{array}{l}v_{x}^{*}=0.4543 M^{* 2 / 3}\left\{\operatorname{Re}_{i} x^{*}\right\}^{1 / 3} \operatorname{Sech}^{2} \xi v_{x, \max }^{*}= \\
0.4543 M^{* 2 / 3}\left(\operatorname{Re}_{i} x^{*}\right)^{1 / 3}\end{array}$ & \\
\hline 10 & Lateral velocity $v_{y}^{*}$ & $\begin{array}{l}v_{y}^{*}=0.5503\left\{\left(M^{*} \operatorname{Re}_{i}\right)^{1 / 3} x^{* 2 / 3}\right\} \\
\times\left\{2 \xi \operatorname{sech}^{2} \xi-\tanh \xi\right\} \\
v_{y}^{*}=0 \text { at } \xi=0 \text { and } \xi=1.0887 \\
v_{\infty, \max }^{*}=0.5503\left\{\left(M^{*} / \operatorname{Re}_{i}\right)^{1 / 3} / x^{* 2 / 3}\right\}\end{array}$ & \\
\hline $11 \mathrm{a}$ & $\begin{array}{l}\text { Mixing layer } \\
\text { thickness, } y_{m}^{*} \\
v_{x} / v_{x, \max }=0.01\end{array}$ & $y_{m}^{*}=10.8765 x^{* 2 / 3} /\left\{R e_{i}^{2 / 3} M^{* 1 / 3}\right\}$ & $\begin{array}{l}\text { Note mix layer varies as } x^{2 / 3} \text { for } 2 \mathrm{D} \\
\text { jet }\end{array}$ \\
\hline $11 \mathrm{~b}$ & $\begin{array}{l}\text { Jet half-width, } \\
y_{1 / 2}^{*} \text { where } v_{x} / v_{x 0}= \\
1 / 2\end{array}$ & $\begin{array}{l}\xi_{1 / 2}=0.8814 \\
y_{1 / 2}^{*}=3.203 x^{* 2 / 3} /\left\{\operatorname{Re}_{i}^{2 / 3} M^{* 1 / 3}\right\}, \text { jet angle } \\
\alpha=\tan ^{-1}\left\{y^{* 1 / 2} / x^{*}\right)\end{array}$ & \\
\hline $11 \mathrm{c}$ & $\begin{array}{l}\text { Velocity contour } \\
v_{x}^{*}=S / v_{x, i}\end{array}$ & $\begin{array}{l}v_{y}^{*}=3.6337\left\{x^{* 2 / 3} /\left(\operatorname{Re}_{i}^{2 / 3} M^{* 1 / 3}\right)\right\} \\
\times \operatorname{Sech}^{-1}\left\{1.4836 x^{* 1 / 6}\left(S / v_{x, i}\right)^{1 / 2} /\left(\operatorname{Re}_{i}^{1 / 6} M^{* 1 / 3}\right\}\right.\end{array}$ & \\
\hline 12 & $\begin{array}{l}\text { Mass flow within or } \\
m(y, x)\end{array}$ & $\dot{m}^{\prime}\left(y^{*}, x^{*}\right) / \dot{m}_{i}^{\prime}=\left\{3.3016 x^{* 1 / 3} M^{* 1 / 3} / R e_{i}^{1 / 3}\right\} \tanh \xi$ & $\begin{array}{l}\text { Used for estimating the mass flow } \\
\text { within } P / 2 \text { for multiple burners }\end{array}$ \\
\hline 13 & Total mass flow $m(x)$ & $\left.\dot{m}^{\prime}\left(\infty, x^{*}\right) / \dot{m}_{i}^{\prime}=\left\{3.3016 x^{*} M^{*} / \operatorname{Re}_{i}\right)^{1 / 3}\right\}$ & \\
\hline 14 & $\begin{array}{l}\text { Height at which two } \\
\text { adjacent mixing layers } \\
\text { intersect }\end{array}$ & $x^{*}=0.009856 P^{* 3 / 2}\left\{\operatorname{Re}_{i} M^{* 1 / 2}\right\}$ & Burners are located $l$ apart \\
\hline $15 \mathrm{a}$ & Air entrained at $x$ & $\dot{m}_{a}^{\prime} / \dot{m}_{i}^{\prime}=\left\{3.3016\left(x^{*} M^{*} / R e_{i}\right)^{1 / 3}\right\}-1$ & \\
\hline $15 b$ & $\begin{array}{l}\text { Air entrained } \\
\text { at } x=\text { mixing layer } \\
\text { intersection height }\end{array}$ & $\begin{array}{l}\dot{m}_{a}^{\prime} / \dot{m}_{i}^{\prime}=\left\{0.70789\left(2 y_{m}^{*}\right)^{/ 2} M^{* 1 / 6}\right\}-1, \\
\dot{m}_{a}^{\prime} / \dot{m}_{i}^{\prime}=\left\{0.70789 P^{* / 2} M^{* 1 / 6}\right\}-1, \\
\text { within interburner spacing/injected flow for } \\
\text { which } y_{m}^{*}=P^{*} / 2\end{array}$ & $\begin{array}{l}\text { Buoyancy affects air entrained for } \\
\text { 2D }\end{array}$ \\
\hline
\end{tabular}


Table 1: Continued.

\begin{tabular}{|c|c|c|c|}
\hline Row\# & Parameter & 2D Jet & Remarks \\
\hline $15 \mathrm{c}$ & $\begin{array}{l}\text { Air entrained at } x= \\
H_{\text {stoich }}\end{array}$ & $\begin{array}{l}\dot{m}_{a}^{\prime} / \dot{m}_{i}^{\prime}=1.5 C J^{*} /\left(\phi_{f}\right)-1 \dot{m}_{a}^{\prime} / \dot{m}_{i}^{\prime} \approx \\
1.5 C J^{*} /\left(\phi_{f}\right) \approx C \\
\dot{m}_{a}^{\prime}(S c) / \dot{m}_{A}^{\prime}(S c=1) \approx C\end{array}$ & \\
\hline 16 & $\begin{array}{l}\text { Species and non } \\
\text { dimensional } \\
\text { Shvab-Zeldovich, } \\
\varphi=\left(b-b_{\infty}\right) /\left(b_{i}-b_{\infty}\right)\end{array}$ & $\begin{array}{l}\varphi(S c=1)=\left\{0.45428\left(\operatorname{Re}_{i} / x^{*}\right)^{1 / 3}\left(J^{*} / M^{* 1 / 3}\right)\right\} \\
\times \operatorname{Sech}^{2} \xi N(S c \pm 1)= \\
\left\{0.45428 C\left(R e_{i} / x^{*}\right)^{1 / 3}\left(J^{*} / M^{*} 1 / 3\right)\right\} \operatorname{Sech}^{2 S c} \xi \\
C=-0.0294 S c^{2}+0.3534 S c+2 / 3\end{array}$ & $\begin{array}{l}b=Y_{F}, Y_{\mathrm{O}_{2}} \text { for mixing, } \\
b=\left\{Y_{F}-Y_{\mathrm{O}_{2}} / \nu_{\mathrm{O}_{2}}\right\},\left\{Y_{F}+C_{p}(T-\right. \\
\left.\left.T_{i}\right) / h_{c}\right\},\left\{Y_{\mathrm{O}_{2}} / \nu_{\mathrm{O}_{2}}+C_{p}\left(T-T_{i}\right) / h_{c}\right\} \\
\text { for species }\end{array}$ \\
\hline $17 \mathrm{a}$ & $\begin{array}{l}\text { Height of Contours, } \\
H^{*}\end{array}$ & $\begin{array}{l}H_{\mathrm{st}}^{*}=H_{f}^{*}=0.09375 R e_{i} C^{3}\left(J^{* 3} / M^{*}\right) / \varphi_{f}^{3} \\
H_{v}^{*}=0.09375 R e_{i} M^{* 2} v_{i}^{3} / S^{3}\end{array}$ & $\begin{array}{l}\varphi_{f}=s /(1+s) \\
s=Y_{\mathrm{O}_{2}, \infty} /\left(\Lambda_{\mathrm{O}_{2}} Y_{F, I}\right) \varphi_{f} 0.0544 \text { for } \\
\text { pure Methane in air } \\
H_{\mathrm{st}}^{*}=H_{f}^{*} \text { for combustion } \\
H^{*}=H / d_{i}\end{array}$ \\
\hline 18 & $\begin{array}{l}\text { Maximum width of } \\
\text { flame, } y_{f, \max }^{*}\end{array}$ & $\begin{array}{l}y_{f, \max }^{*}=\left\{0.7499\left(\gamma \operatorname{Sech}^{4 S c} \gamma\right)\right\}\left(J^{* 2} / M^{* 4 / 3}\right)\left(C / \varphi_{f}\right)^{2} \\
\left(\text { valid when } \rho \text { is constant } 0<y<y_{f}\right)\end{array}$ & \\
\hline 19 & $\begin{array}{l}\text { Ratio of flame height } \\
\text { and max width } \\
\left(H^{*} / y_{f, \text { max }}^{*}\right)\end{array}$ & $\begin{array}{l}H_{f}^{*} / y_{f, \max }^{*}= \\
0.125 R e_{i} C\left(J^{*} M^{* 1 / 3}\right) /\left\{\varphi_{f}\left(\operatorname{Sech}^{4 S c} \gamma\right)\right\} \text { (valid when } \\
\left.\rho \text { is constant and } 0<y<y_{f}\right)\end{array}$ & \\
\hline 20 & $\begin{array}{l}\text { Distance } x_{f, \mathrm{mw}}^{*} \text { at } \max \\
\text { width }\end{array}$ & $\begin{array}{l}x_{f, \mathrm{mw}}^{*}=x_{f, \mathrm{mw}}^{*} \operatorname{Sech}^{6 S c} \gamma, \text { where, } \\
\gamma \tanh \gamma=1 /(4 S c) \text { transcendental equation } \\
\left.\text { (valid when } \rho \text { is constant and } 0<y<y_{f}\right)\end{array}$ & \\
\hline 21 & $x_{f, m w}^{*} / H_{\text {flame }}^{*}$ & $\begin{array}{l}x_{f, \mathrm{mw}}^{*} / H_{f}^{*}=\operatorname{Sech}^{6 S c}(\gamma S c) \text { (valid when } \rho \text { is constant } \\
\left.\text { and } 0<y<y_{f}\right)\end{array}$ & \\
\hline 22 & $\begin{array}{l}\text { Flame angle with axis, } \\
\theta^{\prime} \text {, at flame tip and } \\
\text { location } \\
x^{*}(\text { Figure } 4(b))\end{array}$ & $\begin{array}{l}\tan \theta_{\text {tip }}^{\prime}=1 /\left(1.6512 S c H_{f}^{* 1 / 3} R e_{i}^{2 / 3} M^{* 1 / 3}\right) \\
\text { where, } \\
\tan \theta_{\text {tip }}^{\prime}=\left(\tan \theta^{\prime}\right)_{\operatorname{tip}}\left(\rho_{f} / \rho_{t}\right) \cdot\left\{\tan \theta^{\prime}\right\}_{\text {tip }}\left(T_{i} / T_{f}\right) \\
\tan \theta_{\text {tip }}^{\prime}=\left\{H_{f}^{*} / x^{*}\right\}^{1 / 3-1 / 6 S c} \tan \theta_{\text {tip }}^{\prime}+(2 / 3) \\
\operatorname{Cosh}^{-1}\left(H_{p l}^{*} / x^{*}\right)^{1 / 6} S c\left(1 / x^{* 1 / 3}\right) /\left(0.2752 R e_{i}^{2 / 3} M^{* 1 / 3}\right) \\
\text { and } \theta_{\text {tip }}^{\prime}=\theta \text { for constant } \rho\end{array}$ & \\
\hline 23 & $\begin{array}{l}\text { Lift-off Height, }\left\{L^{*}\right. \\
\left./ H_{\text {flame }}^{*}\right\}\end{array}$ & $\begin{array}{l}L^{*} / H_{f}^{*}=\left[\left\{S / v_{i}\right\}\left\{C J^{*} /\left(\varphi_{f} M^{*}\right)\right\}\right]^{3 S c /(1-S c)} \\
\text { For } S c=1, L^{*} \rightarrow \infty\end{array}$ & $\begin{array}{l}\text { Set } L^{*}=H_{f}^{*} \text { for blow-off; } \\
L^{*}=\text { lift-off height for } S c>1, \\
L^{*}=L_{\text {ig }}^{*} \text { ignitable height for } S c<1\end{array}$ \\
\hline 24 & Blow-off velocity & $v_{\text {blow }}=S C J^{*} /\left(\varphi_{f} M^{*}\right)$ & \\
\hline
\end{tabular}

The $(A: I)$ represents the stoichiometric air to injected gas (fuel + inerts) ratio. If $y_{\mathrm{st}}^{*}$ is set to zero, then the height of stoichiometric contour $H_{\mathrm{st}}^{*}=H_{f}^{*}$ can be determined as shown in row 17. Typical stoichiometric contour is shown as dashed line in Figure 5.

4.3. Velocity Contour. Using the solution given in row 9 for axial velocity $v_{x}^{*}$, one can plot velocity contours by setting $v_{x}^{*}=0.55-0.79$ as shown in solid lines in Figure 4(a). In this particular plot, $H_{\mathrm{st}}^{*}=10$ and $R e_{i}=2.77$. Note that the centerline velocity decreases with $x^{* 1 / 3}$ as shown in row 9 . If $v_{i}=50 \mathrm{~cm} / \mathrm{s}$, then $v_{x}^{*}=0.69$ represents the velocity contour $v_{x}=35 \mathrm{~cm} / \mathrm{s}$ (KAB in Figure 4(a)) which is same as flame velocity for stoichiometric Methane-air mixture. Hence the intersection of this velocity contour with stoichiometric contour at point $K$ represents the anchoring position of the flame or lift-off height $L^{*}$.

The solution for $v_{x} / v_{x, i}$ along the stoichiometric contour can also be determined. However, of greater interest is the velocity contour $y_{v}^{*}\left(x^{*}\right)$ where $v_{x}=$ flame velocity, $S$, given in row 9 , can be plotted by solving for $\xi$ and eventually $y^{*}$ using row 6 . The resulting expression is given below:

$$
\begin{aligned}
y_{v}^{*}= & \left(\frac{x^{* 2 / 3}}{0.2752 \operatorname{Re}_{i}^{2 / 3} M^{* 1 / 3}}\right) \\
& \times \operatorname{sech}^{-1}\left[\left(\frac{S x^{* 1 / 3}}{0.4543 v_{x, i} \operatorname{Re}_{i}^{1 / 3} M^{* 2 / 3}}\right)^{1 / 2}\right] .
\end{aligned}
$$

Equation (5) gives the velocity contour at which the axial gas velocity is equal to the laminar flame speed. Here afterwards, such a contour will be called flame speed contour. By setting $y_{v}^{*}=0, H_{v}^{*}$ can be determined from (5) as shown in row 17.

4.4. Reynolds Number Dependence on Stoichiometric and Flame Speed Contour Growth. The flame speed and stoichiometric contour growth, for a fixed $S c$ are qualitatively 


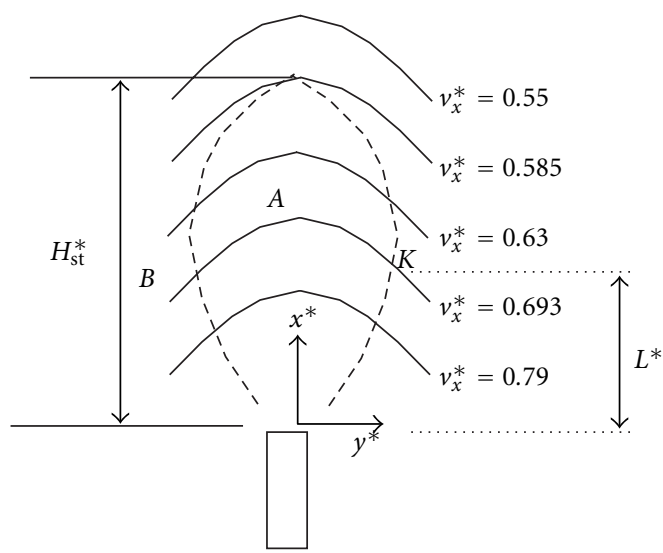

(a) Velocity contours for $H^{*}=10$ and $R e=2.77(S c>1)$

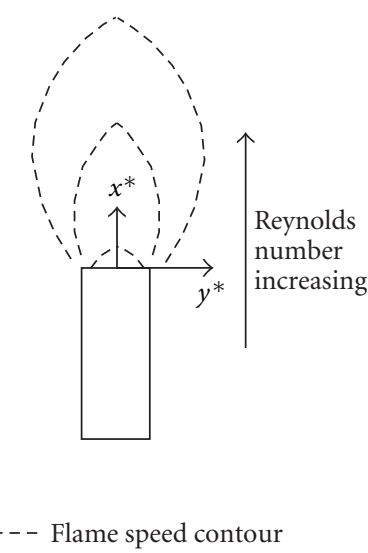

(b) Flame speed contour

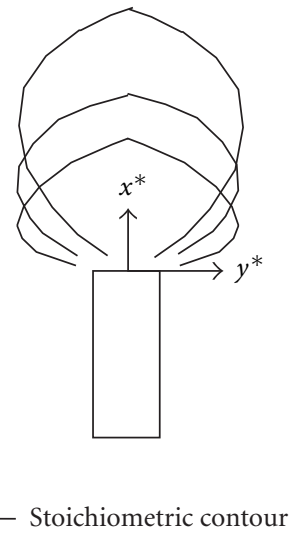

(c) Stoichiometric contour

FIgURE 4: Qualitative growth of the flame speed and stoichiometric contours with Re.

shown in Figures 4(b) and 4(c). As shown in the figures, the flame speed contour elongates and widens when the Re is increased (Figure 4(b)), while the stoichiometric contour elongates and remains of constant width when $R e$ is increased (Figure 4(c)).

4.5. Lift-Off and Blow-off Solutions: Discussion of Schmidt Number Dependence. The Schmidt number $(S c)$ governs the way the two contours grow with respect to one another. Physically, $S c$ represents the ratio of the momentum to the mass diffusion. If $S c=1$, then mass and momentum diffuse equally and the two contours never intersect. Figures 5(A)a5(A)e show how the contours grow with respect to one another as the injection Reynolds number is increased for $S c=1$. If $R e$ is very low (Figures $5(\mathrm{~A}) \mathrm{a}$ and $5(\mathrm{~A}) \mathrm{b}$ ), then the stoichiometric contour (dashed line) will lie on the "outside" of the flame speed contour and stable flame is formed since $v_{x}<S$ everywhere at low $R e$. At a critical $R e$, the two contours will lie directly on top of one another (Figure $5(\mathrm{~A}) \mathrm{c})$. If $R e$ is increased further then the stoichiometric contour will lie "inside" the flame speed contour and blowoff will be achieved (Figures 5(A)d and 5(A)e). Given this discussion, blow-off is assumed to occur when the two contours lie directly on top of one another as shown in Figure 5(A)c. Notice from Figure 5(A) that in each frame, the stoichiometric contour and the flame speed contour are proportional to one another (contours never intersect). Since the contours never intersect, flames for $S c=1$ fuels are either stable or anchored at the burner base or blown off. Lifted flames are not possible for fuels with $S c=1$. Also notice that even though momentum and mass are diffusing equally, the rate of growth for each contour $\left(H_{\text {stoich }}^{*} / H_{\text {flame }}^{*}\right)$ is different for a given $R e$ (this can be seen from row 17).

If $S c \neq 1$, mass and momentum diffuse at different rates, the two contours will intersect at some distance, $x^{*}$ away from the burner given that the injection velocity is sufficiently high. Figures 5(B)a-5(B)e show growth of the stoichiometric and velocity contours with velocity $v_{x, i}$ when
Sc $>1$ and Figures 5(C)a-5(C)e show the corresponding results when $S c<1$. The intersection point corresponds to the lift-off height for $S c>1$ (Figure 5(B)) and the partial flame height (but not the lift-off height) for $S c<1$ (Figure $5(\mathrm{C})$ ). For low injection Re, (Figures 5(B)a and 5(B)b) the stoichiometric contour lies on the "outside" of the flame speed contour (stable flame). As the injection Re is increased further, the two contours intersect as some distance above the burner $L^{*} . L^{*}$ is the lift-off height. In Figure 5(B)c, the flame speed contour lies "outside" of the stoichiometric contour for $x^{*}<L^{*}$ since $v_{x}>S$ everywhere for $y^{*}<y_{f}^{*}$. Therefore, the flame cannot exist between the burner exit and the intersection point. However, for $x^{*}>L^{*}$ the contours switch positions and the flame speed contour lies "inside" the stoichiometric contour, a stable configuration. Therefore, the intersection point corresponds to the lift-off height for Sc $>1$.

For $S c<1$, the following interesting scenario occurs. At a low velocity, the flame speed contour lies "inside" the stoichiometric contour giving rise to a stable flame (Figures $5(\mathrm{C}) \mathrm{a}$ and $5(\mathrm{C}) \mathrm{b})$ meaning the mixture could be ignited and stabilized at any $x^{*}$ along the stoichiometric contour from the burner base to the tip of the stoichiometric contour $\left(H^{*}\right)$. At a certain velocity $\left(v_{\text {crit }}\right)$ the flame speed contour and the stoichiometric contours intersect at their respective tips (Figure $5(\mathrm{C}) \mathrm{c}$ ) marking the last position where the mixture is ignitable along the stoichiometric contour within $0<x^{*}<H^{*}$. Beyond the critical velocity, the flame speed and stoichiometric contours intersect at $L^{*}$ as shown in Figure 5 (C)d. If $S c<1$, for $x^{*}<L^{*}$, the flame speed contour lies on the "inside" of the stoichiometric contour, a stable configuration. For $x^{*}>L^{*}$, the flame speed contour lies on the "outside" of the stoichiometric contour, an unstable configuration. Therefore, for a $S c<1$ mixture with $v_{x, i}$ greater than the critical velocity, the mixture can be ignited and stabilized along the stoichiometric contour only for $x^{*}<$ $L^{*}$. The flame cannot propagate beyond $x^{*}>L^{*}$, if the laminar flame speed $(S)$ is assumed to remain constant, and as such $L^{*}$ will be called the ignitable height or the partial flame height. It is important to state that partial flames 


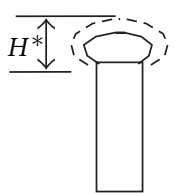

(a)

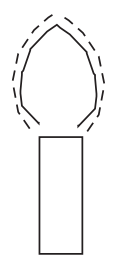

(b)

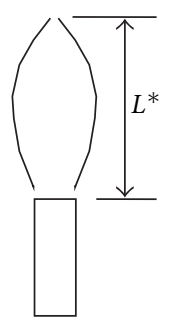

(c)

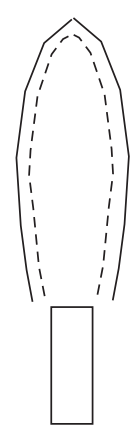

(d)

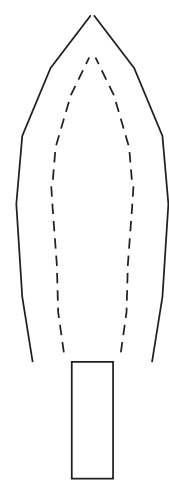

(e)

(A) $S c=1$

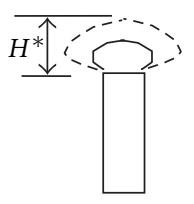

(a)

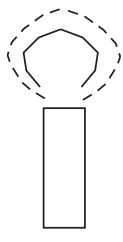

(b)

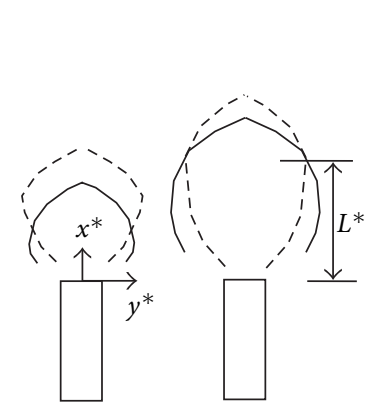

(c) (d)

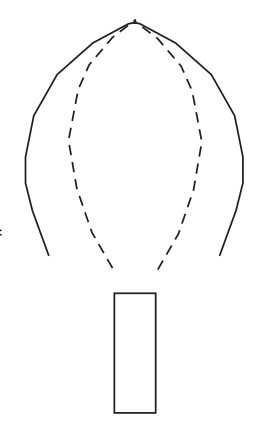

(e)

(B) $S c>1$
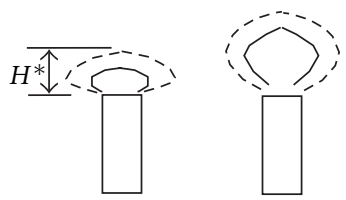

$V_{x}=S$

- - Stoichiometric

(a)

(b)

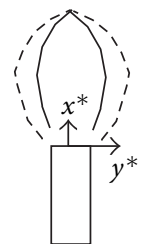

(c)
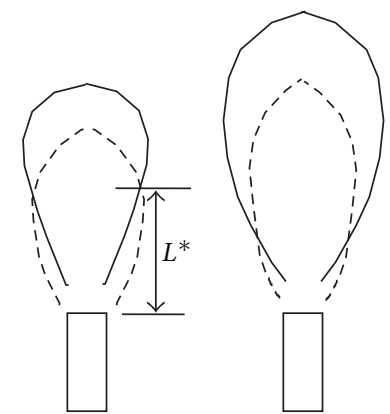

(d)

(C) $S c<1$

FIgURE 5: Stoichiometric (dashed) and flame speed (solid) contour growths with increasing Re and varying Sc.

(which occur when $S c<1$ and $v_{x, i}>v_{x, i, c r i t}$ for $S=$ constant) have not been observed experimentally for $\mathrm{CH}_{4}$ flames $(\mathrm{Sc}=$ 0.74 ) beyond the critical velocity. Tests conducted by Tillman et al. [14] on a linear array of three stainless steel circular burners fired with pure $\mathrm{CH}_{4}$ showed that neither lift-off height nor partial flame height was observed before blowoff for the $\mathrm{CH}_{4}$ flames. However, it must be stated that in the case of combustion, $S$ will be strongly affected by temperature and weakly affected by burnt gas composition.
As such, $S$ will probably increase as the flame temperature increases. Hence, it is possible that during combustion, the flame can be stabilized beyond $L^{*}$ for $v_{x, i}>v_{x, i, c r i t}$ for $S c<1$ fuels.

From the above discussion, an explicit solution can be found for the lift-off height (or unignitable height) if $S c>1$ or partial flame height (or ignitable height) if $S c<1$. The solution comes from finding the intersection of the stoichiometric contour given in (2) and 
the flame speed contour given in (5) and can be found below:

$$
\begin{array}{ll}
\frac{L^{*}}{H_{f}^{*}}=\left[\frac{S}{v_{x, i}}\left(\frac{C J^{*}}{\phi_{f} M^{*}}\right)\right]^{3 S c /(1-S c)}, \quad S c>1, \\
\frac{L_{i g}^{*}}{H_{f}^{*}}=\left[\frac{S}{v_{x, i}}\left(\frac{C J^{*}}{\phi_{f} M^{*}}\right)\right]^{3 S c /(1-S c)}, \quad S c<1 .
\end{array}
$$

The flame height is nondimensionalized by the diameter $\left(d_{i}\right)$ of the planar jet $H_{f}^{*}=H_{\mathrm{st}}^{*}$ is given by the maximum height of the stoichiometric contour, found by setting $\xi=$ $\xi_{\mathrm{st}}^{*}=0$ in row $16, v_{x, i}=$ the average injection velocity, $S=$ the laminar flame speed, $C$ is given in row $16, \phi_{f}$ is given in $(3 \mathrm{a}), M^{*}$ is given in row 2 , and $J^{*}$ is given in row 3 . The $S c$ dependence of $(6 a)$ and $(6 \mathrm{~b})$ is shown in Figure 6 for $\mathrm{N}_{2}$-diluted mixtures of $\mathrm{C}_{3} \mathrm{H}_{8}(\mathrm{Sc} \approx 1.3)$ and $\mathrm{N}_{2}$-diluted mixtures of $\mathrm{CH}_{4}(\mathrm{Sc} \approx 0.74)$, respectively. Note that $(6)$ does not predict lifted flames for $S c=1$. As previously explained, the flame speed and stoichiometric contours do not intersect because mass and momentum diffuse equally. Also note from (6a) and Figure 6 that if $S c>1$, increasing $v_{x, i}$ results in increasing the $L^{*} / H^{*}$ ratio. Since $H^{*} \propto v_{x, i}$, then $L^{*} \propto v_{x, i}^{(1-4 S c) /(1-S c)}$ and hence at $S c=1.3, L^{*} \propto v_{x, i}^{14}$. This shows that lift-off height is a strong function of injection velocity, hence, as the injection velocity is increased, the liftoff height increases to a large value rapidly. However, if the $S c<1$, then increasing $v_{x, i}$ results in decreasing the $L_{i g}^{*} / H_{f}^{*}$ ratio or the ignitable height decreases (i.e., the mixture can only be ignited closer and closer to the burner as the velocity increases). For $S c=0.74, L^{*} \propto v_{x, i}^{-7.5}$. The reason for the negative exponent is as follows. $\mathrm{Sc}<1$ means mass diffuses at a faster rate than momentum. Hence, the fuel diffuses more rapidly than momentum in the radial direction near the burner. A combustible mixture in a low-velocity regime is readily formed. Despite further downstream of the burner, enough mass has diffused so that the stoichiometric contour must form at a lateral distance $y$ closer to the axis of the jet where the axial gas velocity is much higher and hence ignition becomes more difficult. Once ignited near the burner exit whether the flame will be stabilized beyond $x^{*}=$ $L_{\text {ig }}^{*}$ depends upon the flame velocity for partially oxidized fuel, $S c$ and temperature of the vitiated mixture.

The blow-off velocity can also be found from (6a). If Sc $>1$, then $L^{*} / H^{*}$ increases with increasing $v_{x, i}$. At a critical $v_{x, i}$, the intersection of the flame speed contour and the stoichiometric contour will occur at the tip of the respective contour (Figures 5(A)c, 5(B)e, and 5(C)c). This marks the last possible intersection point for the two contours and hence the last possible stable configuration for the flame. Hence, at blow-off, $L^{*}=H^{*}$, setting which in (6a) and solving for $v_{x, i}$ leads to

$$
v_{x, i, \text { blow }}=\frac{S J^{*} C}{\phi_{f} M^{*}} \quad \text { for } S c>1 .
$$

This simple expression allows for the blow-off velocity to be found as a function of the $S c$ ( $C$ also has dependence on $S c$ ) and fuel properties (laminar flame speed $\phi_{f}$ etc.). When

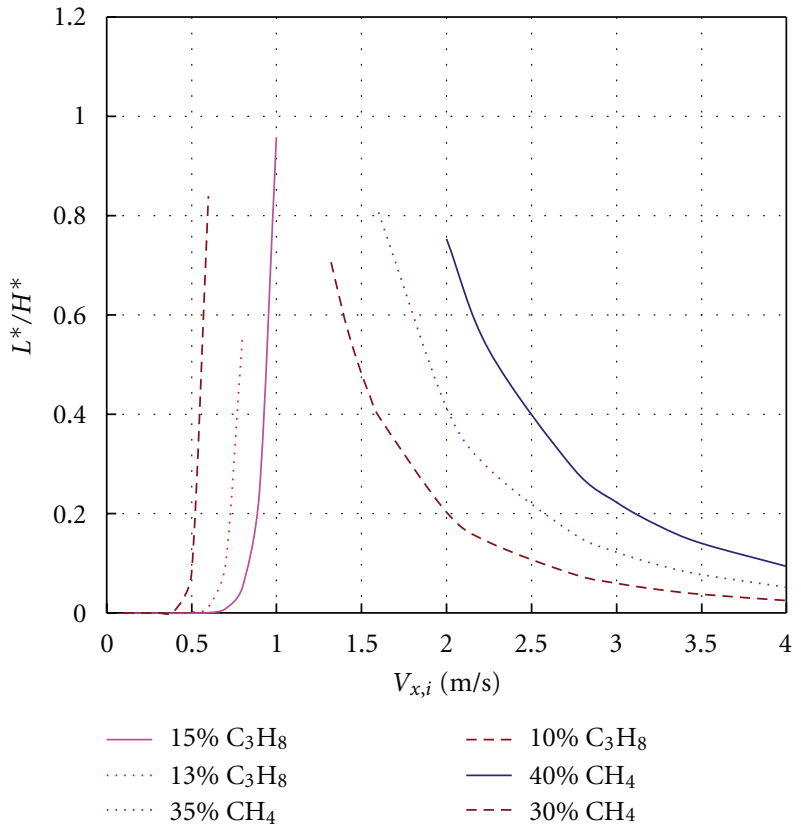

Figure 6: Theoretical predictions for $L^{*} / H^{*}$ ratio as given by (6). The group of lines on the left correspond to diluted $\mathrm{C}_{3} \mathrm{H}_{8}$ mixtures ( $S c \approx 1.3$ and $\mathrm{N}_{2}$ percentages of $85 \%, 87 \%$, and $90 \%$ ) and those on the right correspond to diluted $\mathrm{CH}_{4}$ mixtures $\left(\mathrm{Sc} \approx 0.74\right.$ and $\mathrm{N}_{2}$ percentages of $60 \%, 65 \%$, and $70 \%$ ).

Sc $<1$, (7) predicts the critical velocity (Figure $5(\mathrm{~A}) \mathrm{c}$ ) at which the ignitable height at which $L_{\mathrm{ig}}^{*}=H^{*}$. The ignitable height keeps decreasing with $v_{i}$. The flame may or may not be stable beyond $L_{\text {ig }}^{*}$. The blow-off characteristics seem to depend upon $S c$, particularly, when $S c>1$, blow-off occurs for $v_{i}>v_{x i}$ due to large amount of air.

4.5.1. Solution for Air Entrainment: Discussion of Schmidt Number Dependence. For application to multiple jets the growth of mixing layer and the ratio of amount air entrained by each jet to the amount of gas injected are very important since they affect oxygen concentration in the interstitial space between the burners. Setting $v_{x} / v_{x, i}=0.01$ in row 9 from Table 1, the mixing layer $y_{m}^{*}$ versus $x^{*}$ can be obtained as shown in row 11 . The conversion of $y^{*}$ to real coordinate $y$ requires decompression of $y^{\prime}$ (row 4) using the temperature profile and ideal gas law for density. The mass flow of gases, per unit width, at any given $x$ is given by

$$
\dot{m}^{\prime}(y, x)=2 \int_{0}^{y} \rho v_{x} d y .
$$

Using the axial velocity solution (given in row 9), the normalized gas flow at any $x$ within specified $y$ is given in row 12 , while the total gas flow at same $x$ within $0<y<\infty$ is given by row 13 . The total air entrained at $x$ is

$$
\dot{m}_{a}^{\prime}=\dot{m}^{\prime}(\infty, x)-\dot{m}_{i}^{\prime}
$$

Row 15a presents the solution for air entrained in normalized form as a function of $x^{*}$. By setting $x^{*}=H_{f}^{*}$ in row 15 a and 
using the relation for $H_{f}^{*}$ from row 17, the air entrained at $x^{*}=H^{*}$ is obtained as in row $15 \mathrm{c}$. It is interesting to note that $C$ defined in row 16 approximately represents the ratio of air entrained at $x=H$ for any $S c$ to the air entrained at $x=H$ for $S c=1$ (row 15c). As $S c \rightarrow 0, C \rightarrow 2 / 3,\left(\dot{m}_{A}^{\prime} / \dot{m}_{i}^{\prime}\right) \rightarrow$ $\left(1 / \phi_{f}-1\right)$ and using $(4)$

$$
\begin{gathered}
\left(\frac{\dot{m}_{A}^{\prime}}{\dot{m}_{i}^{\prime}}\right) \longrightarrow(A: F)_{\mathrm{st}} \quad \text { if } Y_{F, i}=1, S c \longrightarrow 0, \\
\left(\frac{\dot{m}_{A}^{\prime}}{\dot{m}_{i}^{\prime}}\right) \longrightarrow(A: I)_{\mathrm{st}} \quad \text { if } Y_{F, i}=1, S c \longrightarrow 0 .
\end{gathered}
$$

For a pure fuel jet, it was seen that as $S c$ approaches smaller values, the air entrained at $x^{*}=H_{f}^{*}$ approaches the stoichiometric amount. For all fuels with $S c=1(C=1)$, the air entrained at $x=H$ to the fuel injected is $50 \%$ in excess of the stoichiometric amount (row 15c). The variation of excess air percentage at $x=H$ (tip of flame) with $S c$ is shown in Figure 7 for 2D and circular jets. See Tillman [13] for circular jet details. For fuels with $S c=1$ at $x=H, 2 \mathrm{D}$ jets entrain $50 \%$ excess air while circular jets entrain 200\% excess air. The mathematical results suggest that excess air percentage at $x=H$ will not change even if fuel is diluted with inerts since $H$ will decrease for the latter. It is seen that excess air percentage is much higher for $\mathrm{C}_{3} \mathrm{H}_{8}$ compared to $\mathrm{H}_{2}$. This will affect the temperature profiles and hence thermal $\mathrm{NO}_{\mathrm{x}}$ [15].

\section{Mathematical Formulation for Multiple Flames}

5.1. Qualitative Discussion of Multiple-Flame Interaction. Interactive processes within liquid drops and coal particle clouds have been dealt in earlier literature $[14,16,17]$. Interacting jet combustion in cross flow [18] and heat transfer characteristics of impinging multiple jets is also studied $[19,20]$. Here, the effect of multiple laminar jets on stability is considered. If multiple single flames are packed closely together, then the flame height, flame width, and flame stability are increased due to the interaction between the burners. For a given burner geometry and combustible fuel, the increase in flame stability is generally a function of two parameters: the spacing between the burners and the average velocity (or Reynolds number) at the burner exit. If the injection velocity is kept constant and the spacing between the burners is reduced, at a critical spacing the flames will begin to interact. Likewise, if the spacing between the burners is kept constant and the injection Reynolds number is increased, at a critical Reynolds number the flames will begin to interact. The first sign of flame interaction is an increase in flame height and an increase in flame width. This is due to a decrease in the oxygen available in the interstitial space between the flames. In other words, each adjacent flame is competing for oxygen and as the spacing is reduced to a certain level or as the injection velocity that is, fuel input rate is increased to a certain level, the available oxygen around the flame begins to decrease. When this occurs, the flames must lengthen and widen to obtain the necessary

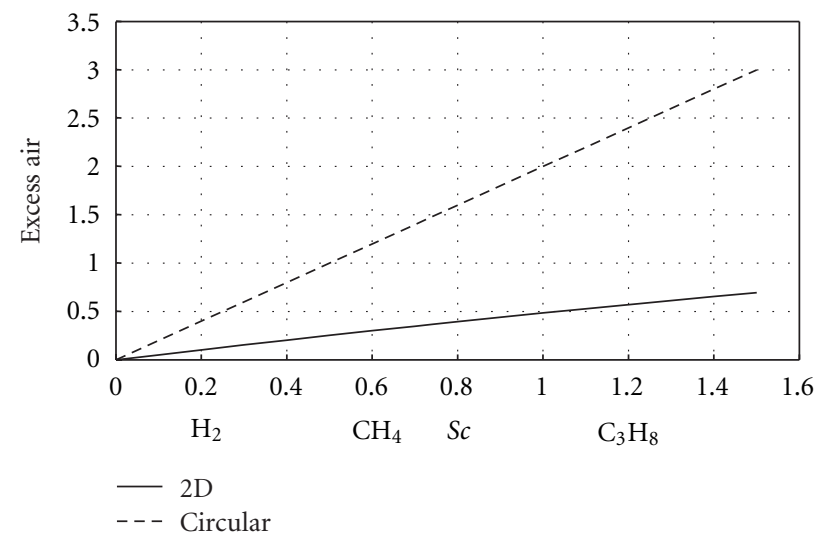

Figure 7: Excess air variation at $x=H$ as a function of $S c$ for 2D and circular jets.

oxygen for completing the combustion, that is, width of the flame will be increased (row 18).

Based on this hypothesis, simple criteria for predicting the stages of interaction can be developed. First, consider Figure 8(a) which shows three 2D burners ( $W$ : west, $C$ : central, and $E$ : east) aligned in a linear array at a spacing of $l_{1}$. The mixing layer, obtained by setting $v_{x} / v_{x, \max }=0.01$ in row 9 for each burner is given by the dashed line. Assuming symmetry in the mixing layer profiles, meaning that the injection velocity for each burner is the same and that the mixing layers themselves are unaffected by the presence of the other flames, then the mixing layers will intersect at a lateral distance of $l_{1} / 2$ at an axial distance of $x_{\text {int }}$. The axial intersection point, $x_{\text {int }}$, is of utmost importance. Since the air required for combustion is entrained within the mixing layer, the flame acts independently as long as $x_{\text {int }} \gg H$. In other words, if $x_{\text {int }} \gg H$, then the flame has the same amount of oxygen, entrained along the mixing layer, from $x=0$ to $x=H$ as it would if the flame were isolated and alone in ambiance. If the interburner spacing were increased to $l \gg l_{1}$, then $x_{\text {int }} \gg H$. Hence, as long as $l \geq l_{1}$ each individual flame acts independently. These flames will be referred to as "isolated" flames similar to the terminology used in droplet and particle combustion literature $[16,17]$. It should be noted that the excess air percentage drawn at $x=H$ varies with the Schmidt number of the injected fuel and the exit plane geometry of the burner (circular or 2D) as shown in Figure 7. As shown in Figure 7, a circular jet with a $S c=1.0$ draws $200 \%$ excess air at $x=H$, while a $2 \mathrm{D}$ jet with $S c=1.0$ only draws $50 \%$. This means that in addition to the injection velocity and the interburner spacing, the Schmidt number of the fuel and the exit plane geometry of each burner also play a role in determining when interaction begins.

The mass fraction of $\mathrm{O}_{2}$ available within the interstitial space between the flames is graphically illustrated in Figure 9 as a function of interburner spacing. As previously explained, for isolated flame behavior the $\mathrm{O}_{2}\left(Y_{\mathrm{O}_{2}, l / 2}\right)$ is the same as the far field $\mathrm{O}_{2}$ concentration $\left(Y_{\mathrm{O}_{2}, \infty}\right)$ for $x=0$ to $x=H$ as shown in Figure 9(a). However, as the spacing is reduced to $l_{2}<l_{1}$ (Figure 9(b)), the mixing layers intersect at $x=K$ 


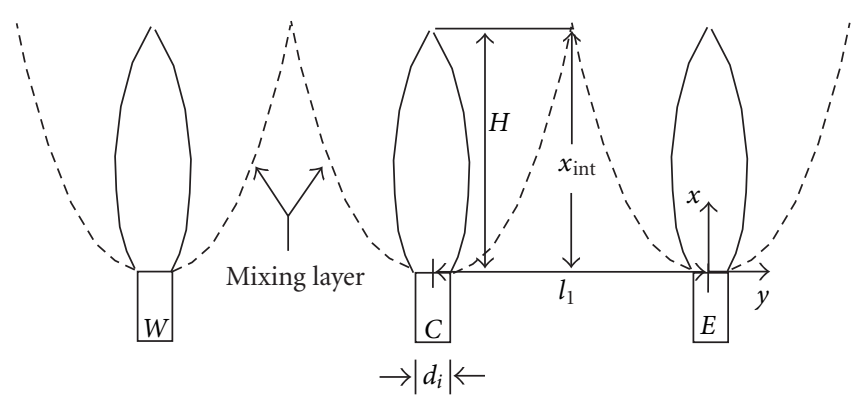

(a) When $l>l_{1}$, each burner operates as a single burner. Recall that $50 \%$ excess air is entrained for 2D burners fired with fuels of $S c=1.0$ when $l>l_{1}$

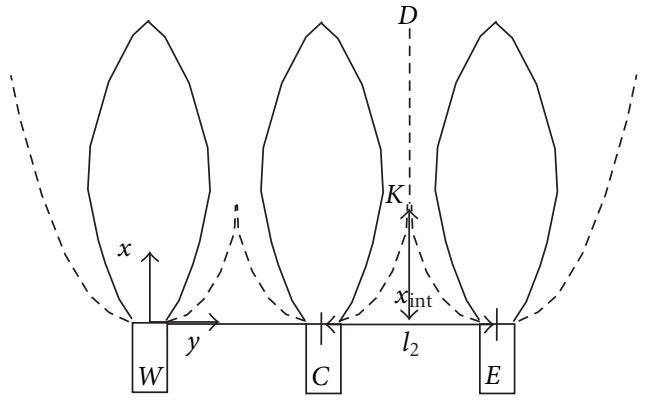

(b) When $x_{\text {int }}<H$, interaction effects the individual flame characteristics, $l_{2}<l<l_{1}$

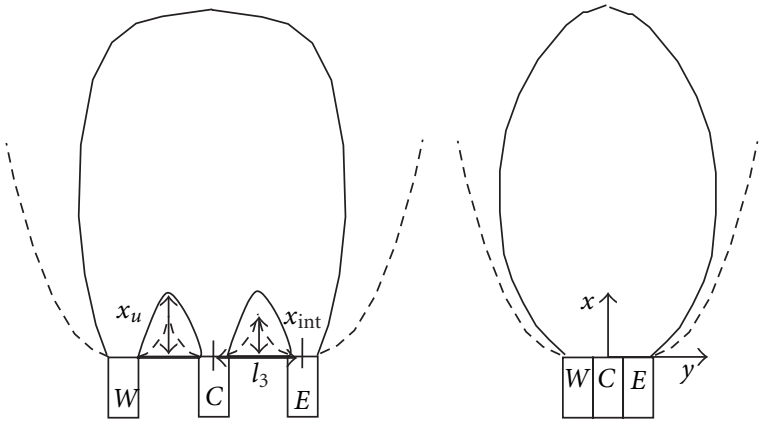

(c) When $l<l_{2}$, the air entrained is insufficient to burn the fuel from the central burner and a group flame is

(d) Sheath combustion all of the required air must formed

FIGURE 8: Qualitative illustration of the effect of flame interaction: (a) isolated flames, (b) individual flames, (c) group flame, and (d) sheath flame.

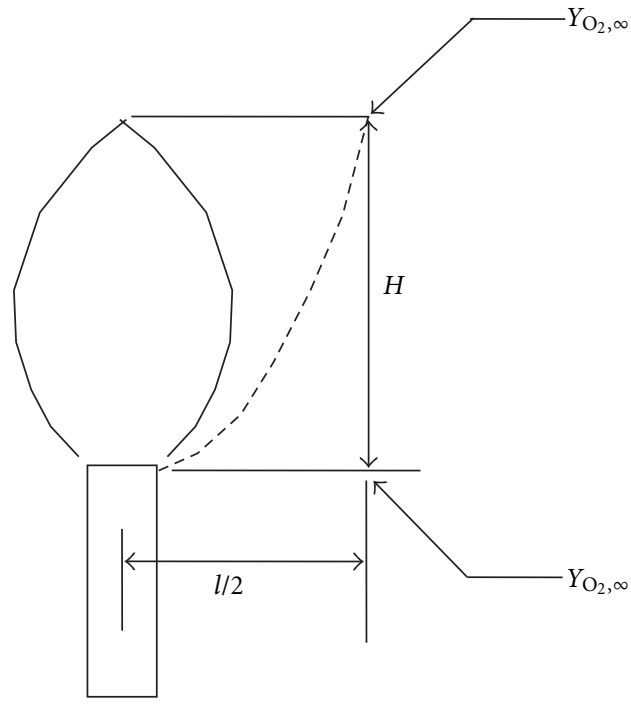

(a) Isolated flame: $Y_{\mathrm{O}_{2}, \infty}=0.23$

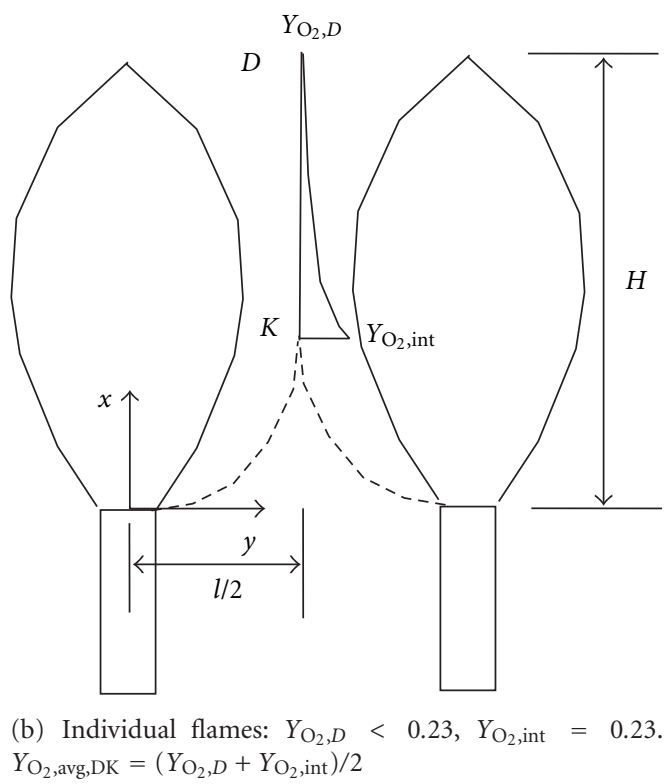

$Y_{\mathrm{O}_{2}, \text { avg,DK }}=\left(Y_{\mathrm{O}_{2}, D}+Y_{\mathrm{O}_{2}, \text { int }}\right) / 2$

FIGURE 9: Oxygen profiles for (a) single flames and (b) multiple flames.

which is less than the flame height $(H)$ and the flames begin to interact (Figure $9\left(\right.$ b) ) due to $\mathrm{O}_{2}$ deficiency in the region $x=K$ to $x=D$. The oxygen deficiency developing in the interstitial space $\left(x_{K}<x<x_{D}\right)$ between the flames is shown in Figure 8(b). Now, the free stream $\mathrm{O}_{2}$ concentration in the interstitial space between the burners in the region of $x=$ $K$ to $x=D$ is less than the far field oxygen concentration. Under these conditions, the flames must widen and lengthen to obtain the necessary oxygen for combustion and will be referred to as interacting "individual" flames. 
As the spacing between the burners is reduced further $\left(l<l_{3}\right)$, the amount of air entrained per burner within the interburner spacing will become insufficient to completely burn the fuel issuing from the central burner, $C$ (Figure 8(c)). At this point, the oxygen concentration at some axial location between the flames reaches zero, and the flames must merge together forming a larger "group" flame. When a group flame forms, the flame structure near the burner (height $x_{u}$ in Figure 8(c)) is similar to an underventilated BurkeSchmann flame. If the spacing is decreased further, to where the tips of the each burner are touching, no flame can exist in the interstitial space and the cluster behaves like a single burner with all of the required air coming from the far field (Figure $8(d)$ ). This type of flame is called a "sheath" flame in analogy with group combustion literature. It is important to state that the interaction hypothesis proposed is based only on the amount of oxygen available in the interstitial space between the flames. Hence, the hypothesis may require modification, particularly for sooty flames where radiation interaction occurs over larger distances.

5.2. Solution for Flame Interaction. Based on the qualitative observations illustrated in Figure 8, an approximate criterion can now be developed to predict at which interburner spacing flame interaction and group flame formation will occur. As shown in Figure 8(a), the last possible position where single flame behavior can be observed is governed by the intersection of the mixing layers (at $l=l_{1}, x_{\text {int }}=H$ ). Therefore, it is necessary to find an equation for the mixing layer profile. The mixing layer is defined as $v_{x}=0.01 v_{x, \max }$. It is assumed that $v_{x, \max }$ always occurs at $y^{*}=0$. Therefore, from row 9:

$$
v_{x, \max }^{*}=\frac{v_{x, \max }}{v_{x, i}}=\frac{0.4545 R e_{i}^{1 / 3} M^{* 2 / 3}}{x^{* 1 / 3}} .
$$

Hence along the mixing layer,

$$
\frac{v_{x}}{v_{x, \max }}=0.01=\operatorname{sech}^{2} \xi .
$$

From (13), solving for $\xi$ at which $v_{x}=0.01 v_{\max }$ gives $\xi=$ 2.993 and using the modified similarity variable $\xi$, as found in row 6 , the mixing layer profile can be found as given in row 11:

$$
y_{\text {mix }}^{*}=\frac{10.8765 x^{* 2 / 3}}{R e_{i}^{2 / 3} M^{* 1 / 3}} .
$$

Note that $y_{\text {mix }}^{*}=y_{\text {mix }}^{\prime} / d_{i}$ and the stretched variable $y^{\prime}=\int_{0}^{y} \rho / \rho_{i} d y$ from row 4 . Hence,

$$
y_{\text {mix }}^{\prime}=\int_{0}^{y \text { mix }} \frac{\rho}{\rho_{i}} d y \approx\left\{\rho_{\text {avg }} \frac{x}{\rho_{i}}\right\} y_{\text {mix }} .
$$

From (14a), (14b) it can be seen that the expansion of gases increases the thickness of mixing layer. If it is assumed that the mixing layer growth is unaffected by the presence of other jets, then the height at which the mixing layers of adjacent jets intersect is given by setting $y_{\text {mix }}^{*}=l^{*} / 2$ in (14a) which gives the axial location of the mixing layer intersection as:

$$
x_{\text {int }}^{*}=0.00986 \ell^{* 3 / 2} \operatorname{Re}_{i} M^{* 1 / 2} .
$$

Given this assumption, as long as $x_{\text {int }}^{*}>H^{*}$, the flames behave independently. Setting $x_{\text {int }}^{*}=H^{*}$ and solving for $l^{*}$ gives the least interburner spacing where single flame behavior will be observed. From the rearrangement of (15a), an isolated flame occurs if:

$$
\ell^{*}>\left[\frac{H^{*}}{0.00986 R e_{i} M^{* 1 / 2}}\right]^{2 / 3},
$$

where the stretched variable $l^{*}=l^{\prime} / d_{i}$ and $l^{\prime}=$ $\int_{0}^{y \text { mix }} \rho / \rho_{i} d y \approx\left(\rho_{\text {avg }} / \rho_{i}\right) l$. Expressing $(15 \mathrm{~b})$ in terms of the physical variable $y$ gives

$$
\ell>d_{i}\left(\frac{\rho_{i}}{\rho_{\text {avg }}}\right)\left[\frac{H^{*}}{0.00986 \operatorname{Re}_{i} M^{* 1 / 2}}\right]^{2 / 3} .
$$

In other words, the expansion of gases requires the interburner spacing to be at a larger distance to form an individual flame. Equation (15c) can also be nondimensionalized by the isolated flame height $H$, as found in row 17. Algebraic manipulation gives the following:

$$
\frac{\ell}{H}>\left(\frac{\rho_{i}}{\rho_{\mathrm{avg}}}\right)\left[\frac{47.87 \phi_{f}}{\mathrm{Re}_{i} C J^{*}}\right],
$$

where $R e_{i}$ is the injection Reynolds number, $C=$ Schmidt number dependent constant defined in row $16, J^{*}$ comes from the conservation of species as given in row 3 , and $\phi_{f}$ from (3a). For typical values of $R e_{i}=10, \phi_{f}=0.05, C=1$, $J^{*}=1$, and $\rho_{i} / \rho_{\text {avg }} \approx 4,(15 \mathrm{~d})$ predicts that interaction will occur when $l / H \leq 0.957$ or when the interburner spacing is approximately equal to the isolated flame height of each burner.

5.3. Solution for Group Flame Formation. The following hypotheses are used in arriving at a criterion for group flame formation.

5.3.1. Isolated Flames Approximation. Following the group combustion literature $[16,17,21]$, a group flame is presumed to form when two flames from adjacent burners touch each other. Hence,

$$
l_{\text {group }}=\frac{W_{\max }}{2}+\frac{W_{\max }}{2}=W_{\max },
$$

where $W_{\max }$ is the maximum width of flame or nondimensionalizing by the isolated flame height, $H$, as found in row 17:

$$
\frac{\ell_{\text {group }}}{H}=\frac{W_{\max }}{H}=\frac{16 \phi_{f} \gamma \operatorname{sech}^{4 S c} \gamma}{R e_{i} C J^{*} M^{* 1 / 3}}
$$

$W_{\max }$ is estimated from the isolated laminar flame theory as given in row 18. Notice that the maximum flame width, given in row 18, is not an explicit function of injection Reynolds 
number. However, at low Reynolds numbers, the Froude number $\left(F r \propto v^{0.5}\right)$ will be low meaning that buoyancy forces will be dominante and $M^{*}$ will increase. If $M^{*}$ increases, then $W_{\max }$ will decrease and $l_{\text {group }}$ will decrease. This leads to the conclusion that (16b) predicts that the interburner spacing at which group flames will form will not be a function of injection Reynolds number if the injection velocity is high enough to cause the flame to be momentum instead of buoyancy driven $(\mathrm{Fr}>1)$. Also notice from row 18 that $W_{\max }$ depends on the oxygen concentration within the interstitial space (given by the $\phi_{f}$ term in row 18). As the burner spacing decreased, the oxygen concentration in the interstitial space decreases (as shown in Figure 8(b)) which causes $\phi_{f}$ to decrease. If $\phi_{f}$ decreases, $W_{\max }$ will increase as shown in row 18. Since under interactive modes the flame width widens, (16a) and (16b) represent the lower bound on the interburner spacing where group flames should be formed for momentum-driven flames.

5.3.2. Insufficient Air in the Interstitial Space. As a second approximation, group flames will be assumed to form when the entrained air becomes insufficient to burn the fuel issuing from the central burner (Figure 8(c)). Recall from Figure 7 that the excess air drawn by the isolated 2D jet at $x^{*}=H^{*}$ is $50 \%$ when $S c=1$. Hence, at $x^{*}<H^{*}$ the excess air percentage will decrease. At some point say $x^{*}=x_{\text {stoich}}^{*}$, the excess air percentage will be zero or in other words, the amount of air entrained will be equal to the stoichiometric amount. Recall from (9) that the total air entrained, per unit depth, at $x$ is given by

$$
\dot{m}_{a}^{\prime}=\dot{m}^{\prime}(\infty, x)-\dot{m}_{i}^{\prime}
$$

Normalizing (17) and recalling $\dot{m}^{\prime}\left(\infty, x^{*}\right) / \dot{m}_{i}^{\prime}$ from row 13,

$$
\frac{\dot{m}_{a}^{\prime}}{\dot{m}_{i}^{\prime}}=\frac{3.3016 x^{* 1 / 3} M^{* 1 / 3}}{R e_{i}^{1 / 3}}-1 \text {. }
$$

Using (9) and (18), the gas entrained within $l^{*} / 2$ for each single burner is given by

$$
\frac{\dot{m}_{A}}{\dot{m}_{i}}=\left(0.70788 \ell^{* 1 / 2} M^{* 1 / 6}\right)-1 .
$$

Setting $\dot{m}_{a}^{\prime} / \dot{m}_{i}^{\prime}=(A: F)_{\text {stoich }} / Y_{F, i}=(A: I)_{\text {stoich }}$ in (19) leads to a simple criterion which can be used to predict the spacing at which group flames will form in an array of 2D burners. A group flame will form when

$$
\left(0.70788 \ell^{* 1 / 2} M^{* 1 / 6}\right)-1<(A: I)_{\text {stoich }} .
$$

Rearranging (20), the spacing $l^{*}$ that leads to group flame formation can be found:

$$
\ell^{*}<\left[\frac{(A: I)+1}{0.70788 M^{* 1 / 6}}\right]^{2} .
$$

Equation (21a) expressed in terms of physical variables is given by

$$
\ell<d_{i}\left(\frac{\rho_{i}}{\rho_{\text {avg }}}\right)\left[\frac{(A: I)_{\text {stoich }}+1}{0.70788 M^{* 1 / 6}}\right]^{2} .
$$

Non-dimensionalizing equation (21b) by the isolated flame height of each burner, $H$, as found in row 17 , gives the following:

$$
\frac{\ell}{H}=\left(\frac{\rho_{i}}{\rho_{\text {avg }}}\right) \frac{21.287\left[(A: I)_{\text {stoich }}+1\right]^{2} \phi_{f}^{3} M^{* 2 / 3}}{R e_{i} C^{3} J^{3}} .
$$

Using typical values of $(A: F)_{\text {stoich }}=17.40, Y_{F, i}=1$, $\phi_{f}=0.05, M^{*}=1.2, R e_{i}=10, C=J=1$, and $\rho_{i} / \rho_{\text {avg }}=4$, (21c) predicts that group flames will form when $l / H=0.41$. This marks an approximate sixty percent decrease in the $l / H$ ratio where the flames first begin interacting as given by (15d).

\section{Experimental Results for Isolated Burner Jets}

6.1. Experimental Apparatus. The experimental apparatus shown in Figure 10 consists of an open-ended, rectangular enclosure in which a stainless steel 2D burner was mounted. The sides of the apparatus were screened with a fine mesh to dampen outside disturbances. The 2D burner tested had a cross section of $0.8 \mathrm{~mm}$ by $6.35 \mathrm{~mm}$ and a length of $610 \mathrm{~mm}$ to allow for a fully developed velocity profile at the burner exit. The burner was fired with $\mathrm{CH}_{4}$ or $\mathrm{C}_{3} \mathrm{H}_{8}$ (usually diluted with air or $\mathrm{N}_{2}$ ) supplied from a pressurized tank. The flow was regulated by a flowmeter with a maximum scale of 6.5 lpm of air. Measurements of flame height, flame width and its axial location were made using a CID 2250 digital camera with a $1 / 30$ second sampling rate and a resolution of 191 pixels/in.

\subsection{Experimental Measurements versus Theoretical Predictions}

6.2.1. Ratio of Maximum Flame Width to Visible Flame Height. Figure 11 shows the ratio of the maximum flame width to the visible flame height as a function of injection $R e_{i}$ for a single $2 \mathrm{D}$ jet fired with $100 \% \mathrm{CH}_{4}$. It is to be noted that parameter ratio $\mathrm{W} / \mathrm{H}$ is used for plotting to reduce property sensitivity. The theoretical predictions for the maximum flame width to visible flame height ratio $\left(y_{f, \max ^{*}} / H^{*}\right)$ are specified in row 19 . Note, however, that the radial coordinate $\left(y^{*}=y^{\prime} / d_{i}\right)$ is a compressed coordinate and as such the transformation given in row 4 is needed to evaluate the actual radial coordinate $(y)$. To evaluate the integral in row 4 , the ratio $\rho / \rho_{i}$ must be known. If the combustion gases are assumed to be ideal with a constant molecular weight, then $\rho / \rho_{i}=T_{i} / T$.

Two possibilities will be considered. First, the gases will be assumed incompressible $\left(\rho / \rho_{i}=1\right.$ and $\left.y^{\prime}=y\right)$. This row is given by the dashed line in Figure 11. Secondly, an average density ratio will be assumed. For this row, $\rho_{\text {avg }} / \rho=$ $T_{i} / T_{\text {avg }} \approx 4$ which implies $y=4 y^{\prime}$. This row is given by the solid line in Figure 11.

Theoretical predictions follow the basic trend of experimental data showing that the ratio decreases as the injection $R e_{i}$ increases. The agreement between theory and experiment is the best at higher $R e_{i}$ since buoyancy forces, which were not 


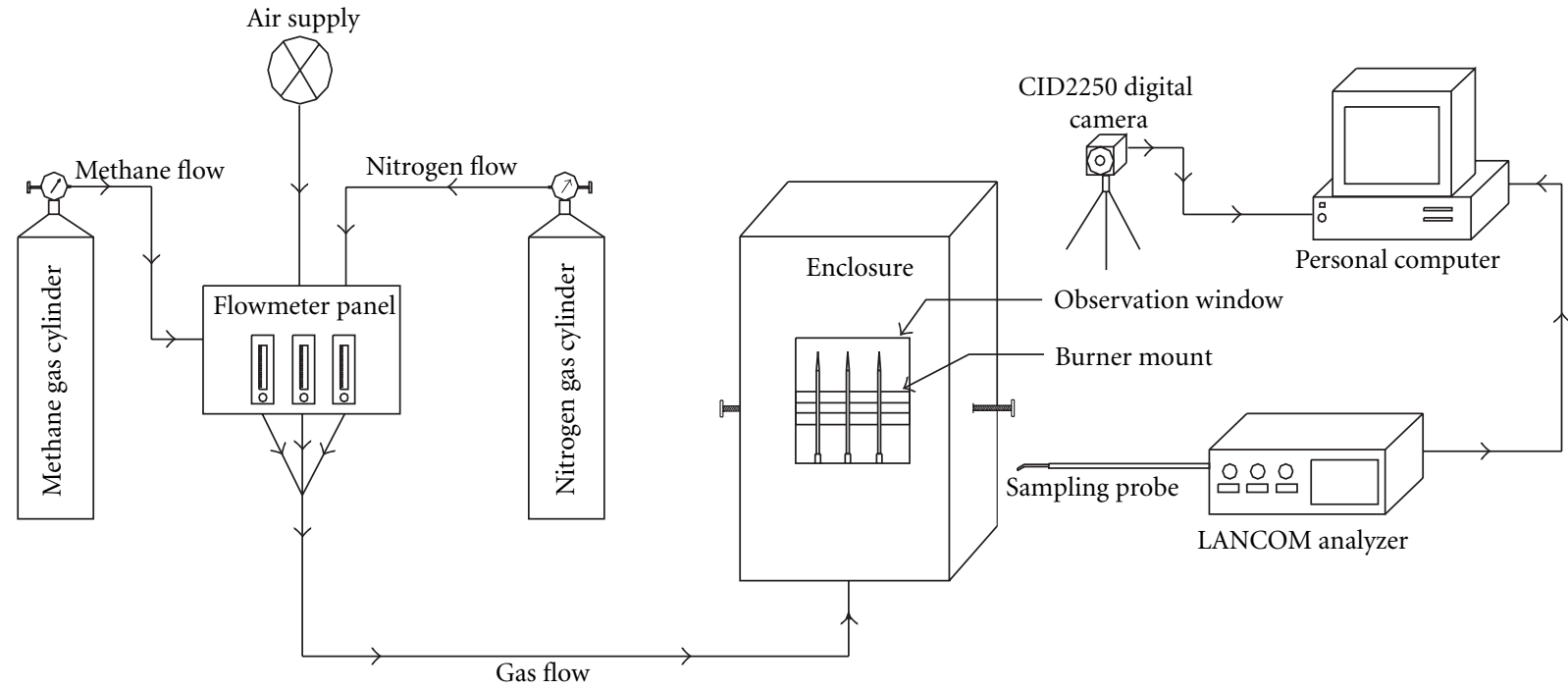

FIGURE 10: Experimental apparatus.

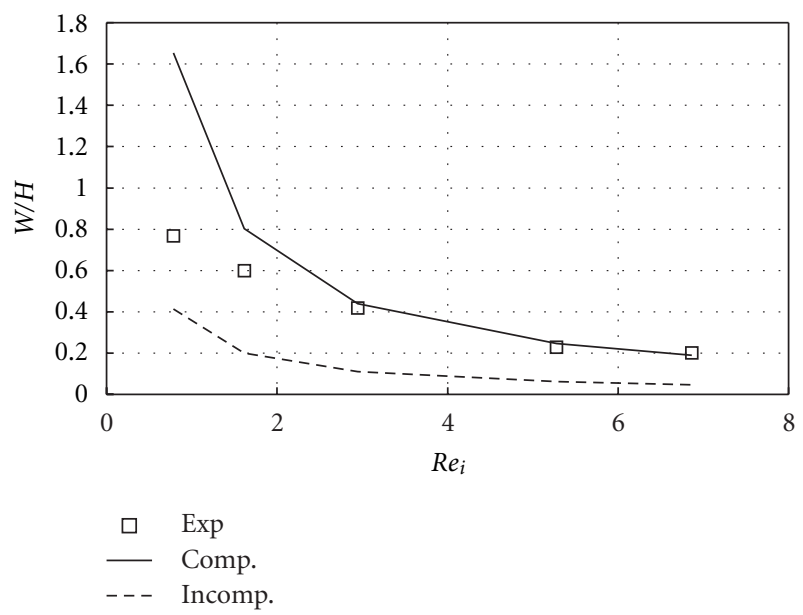

FIgURe 11: Ratio of maximum flame width to visible flame height as a function of injection $\mathrm{Re}$ for a single 2D jet fired with $100 \% \mathrm{CH}_{4}$.

included in the analytical expressions, will become negligible with increasing injection velocity. The Froude number, $\mathrm{Fr}$, as defined in row 2, was used to determine the ratio of the momentum forces to the buoyancy forces. Calculated $\mathrm{Fr}$ at each $R e_{i}$ is tabulated in Table 2 .

It can be observed from the table that buoyancy forces appear to be important $(F r<1)$ at all locations. However, ignoring buoyancy forces may become critical only after $F r$ falls below 0.4 (when $R e_{i}=2.95$ ). For $R e_{i}$ beyond 2.95 , the theory and experiment are compared favorably as previously mentioned. In Figure $11, M^{*}=1.20$ was used, corresponding to nonbuoyant conditions for a laminar, parabolic velocity profile at the burner exit. Under buoyant conditions, $M^{*}$ should be greater than 1.20. If $M^{*}$ increases, then row 19 shows that $W^{*} / H^{*}$ decreases which may explain the differences between the theory and the experiment at lower injection $\mathrm{Re}$. Sc for $\mathrm{CH}_{4}$ used in row 19, was calculated to be 0.74 based on a stoichiometric mixture of $\mathrm{CH}_{4}$ and air, and all gas properties were evaluated at $700 \mathrm{~K}$.

6.2.2. Ratio of Axial Location of Maximum Flame Width to Visible Flame Height. Figure 12 shows the ratio of the axial location where the maximum flame width occurs to the visible flame height as a function of injection velocity for a single $2 \mathrm{D}$ jet fired with $100 \% \mathrm{CH}_{4}$. The solid line on the graph represents the laminar flame theory predictions found in row 21. For these predictions, $S c$ was evaluated to be 0.74 based on a stoichiometric mixture of $\mathrm{CH}_{4}$ and air. Note from row 21 that the theory predicts no injection velocity or injection $R e_{i}$ dependence. However, experimental data shows that as the injection $R e_{i}$ increases, the ratio of the axial location at the maximum flame width to the visible flame height decreases up until $R e_{i}=3$ and then increases again. If the injection $R e_{i}$ is very low, the maximum flame width occurs at approximately half the flame height. As the injection $R e_{i}$ increases up to approximately 3.0, the axial location at which the maximum flame width occurs becomes a smaller fraction of the total flame height. In other words, the flame remains wide near the base of the burner as it continues to lengthen. However, as injection $R e_{i}$ is increased beyond 3.0, the flame starts to become wider at the flame tip meaning the ratio of $x_{\max }^{*} / H^{*}$ begins to increase.

6.2.3. Lift-Off Height Measurements with Nitrogen-Diluted $\mathrm{C}_{3} \mathrm{H}_{8}$ Mixtures. As previously discussed in Section 4, no lifted flames were observed when the 2D jet was fired with $\mathrm{CH}_{4}$. However, lifted flames were observed for propane mixtures $(S c \approx 1.3)$. The lift-off height to flame height ratio for a single $2 \mathrm{D}$ jet fired with an $85 \% \mathrm{~N}_{2}-15 \% \mathrm{C}_{3} \mathrm{H}_{8}$ by volume mixture is shown in Figure 13. The percentage of nitrogen dilution was selected to allow lift-off to occur in the laminar regime. As shown in the figure (solid line) and given in the theory (row 23), lift-off height increases as the injection velocity is increased. $S c$ for the fuel mixture (as used 
TABLE 2: Calculated Froude number versus Reynolds number for isolated jet.

\begin{tabular}{|c|c|c|c|c|c|}
\hline Froude number, $F r$ & 0.167 & 0.283 & 0.383 & 0.489 & 0.537 \\
\hline Injection Reynolds number, $R e_{i}$ & 0.784 & 1.62 & 2.95 & 5.28 & 6.86 \\
\hline
\end{tabular}

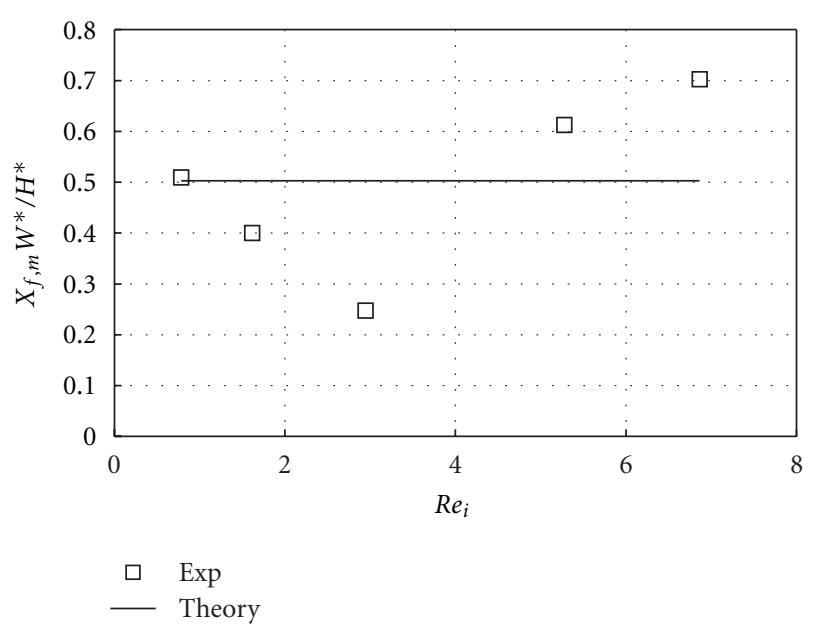

FIGURE 12: Ratio of axial location of the maximum flame width to the visible flame height as a function of injection $\mathrm{Re}_{i}$ for $100 \% \mathrm{CH}_{4}$ fuel.

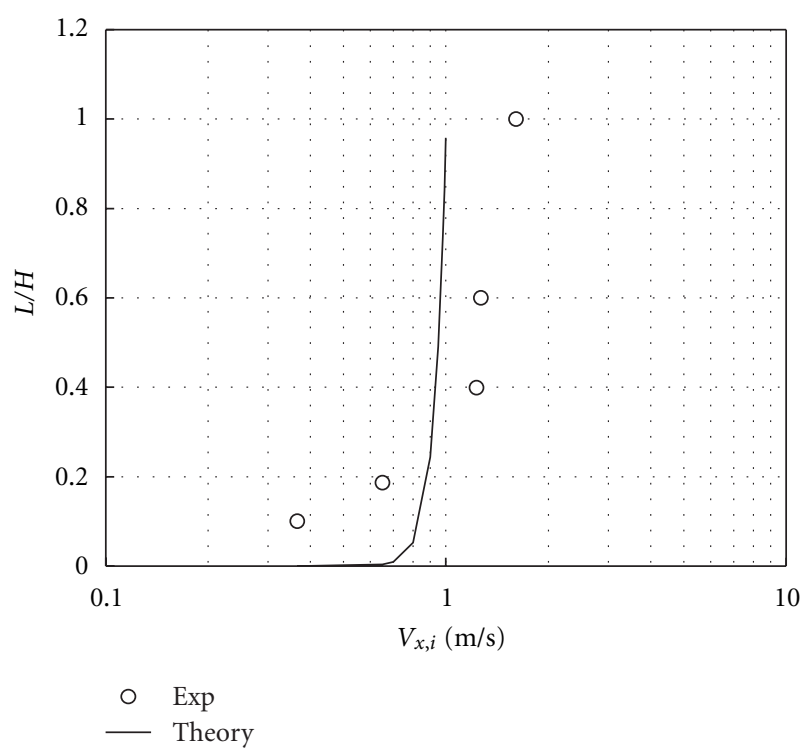

Figure 13: Lift-off height for $85 \% \quad \mathrm{~N}_{2}-15 \% \quad \mathrm{C}_{3} \mathrm{H}_{8}$ by volume mixture, $S c=1.30$.

in row 23) was taken to be 1.30 based on a stoichiometric mixture of $\mathrm{C}_{3} \mathrm{H}_{8}$ and air. $M^{*}$ in row 23 was selected to be 1.20 representing nonbuoyant conditions, and the laminar flame speed was taken to be $0.25 \mathrm{~m} / \mathrm{s}$ based on experimental measurements [6]. The theory tends to predict lift-off at a later injection velocity than the experiment and also shows a steeper increase in lift-off height.
6.2.4. Blow-Off Velocity for Nitrogen-Diluted $\mathrm{C}_{3} \mathrm{H}_{8}$ Mixtures. The comparison between the laminar flame theory's prediction of blow-off velocity (as given in row 24) and the experimental measurements of blow-off for a single $2 \mathrm{D}$ jet fired with $\mathrm{N}_{2}$-diluted mixtures of $\mathrm{C}_{3} \mathrm{H}_{8}$ is given in Figure 14. For the theoretical predictions, $M^{*}=1.20, J^{*}=1.0$, and $S$ was taken to be $0.20,0.23$, and $0.25 \mathrm{~m} / \mathrm{s}$ for $90 \% \mathrm{~N}_{2}-10 \%$ $\mathrm{C}_{3} \mathrm{H}_{8}, 87 \% \mathrm{~N}_{2}-13 \% \mathrm{C}_{3} \mathrm{H}_{8}$, and $85 \% \mathrm{~N}_{2}-15 \% \mathrm{C}_{3} \mathrm{H}_{8}$ mixtures based on experimental data collected in [6]. As shown in the figure, the theory underpredicts the blow-off velocity by a factor of about 1.40. It is encouraging, however, that the theory does show the same trends as the experimental data. As the mixture is leaned, both the theory and the experiment show a similar decrease in blow-off velocity.

Recently a test method was proposed to determine the degree of flammability of refrigerants [20]. Higher the flame speed $(S)$ of a fuel, higher the flammability of fuel. Looking at the expression for blow-off velocity $v_{\text {blow }}$ (row 24) and liftoff height $L$ (row 23), it is seen that $v_{\text {blow }} \propto C(S c) S$, while $L \propto S^{3 S c /(S c-1)}$. For Propane fuels, $S c \approx 1.30, C=1.076$, and hence $v_{\text {blow }} \propto 1.076 S$, while $L \propto S^{12}$ for $2 \mathrm{D}$ jet $(L \propto$ $S^{4}$ for a circular jet). Thus, lift-off height is more sensitive to flammability than blow-off. Therefore, the current lift-off height may be used to distinguish the degree of flammability of different refrigerants. One can increase the sensitivity by diluting fuel with inerts since it affects $\phi_{f}$.

\section{Experimental Results for Multiple Burner Jets}

7.1. Experimental Apparatus. The experimental apparatus shown in Figure 10 was modified to an open-ended, rectangular enclosure in which three stainless steel 2D burners were mounted coaxially in a linear, triple burner array (TBA). The burner dimensions remain the same as in the earlier experiments. Interburner spacing is variable with a resolution of $1 / 8 \mathrm{in}$. The three burners were fired with equal amounts of $\mathrm{CH}_{4}$ or $\mathrm{C}_{3} \mathrm{H}_{8}$ supplied from a pressurized tank. Shop air and $\mathrm{N}_{2}$ were available for dilution. Experimental results and relevant discussions will be divided into four sections which will identify: (i) the interactive modes in multiple 2D jets, as a function of injection Reynolds number and interburner spacing, (ii) the interaction and group flame formation criteria, (iii) the changes in flame structure (flame height and width) under interactive modes, and (iv) the changes flame stability (lift-off height and blow-off velocity) under interactive modes.

\subsection{Interactive Modes in Multiple 2D Jets}

7.2.1. Ratio of Multiple Flame Height to Single-Flame Height. Figure 15 shows the ratio of the height of the multiple flames $\left(H_{m}\right)$ to the height of an isolated flame $(H)$ as a function 


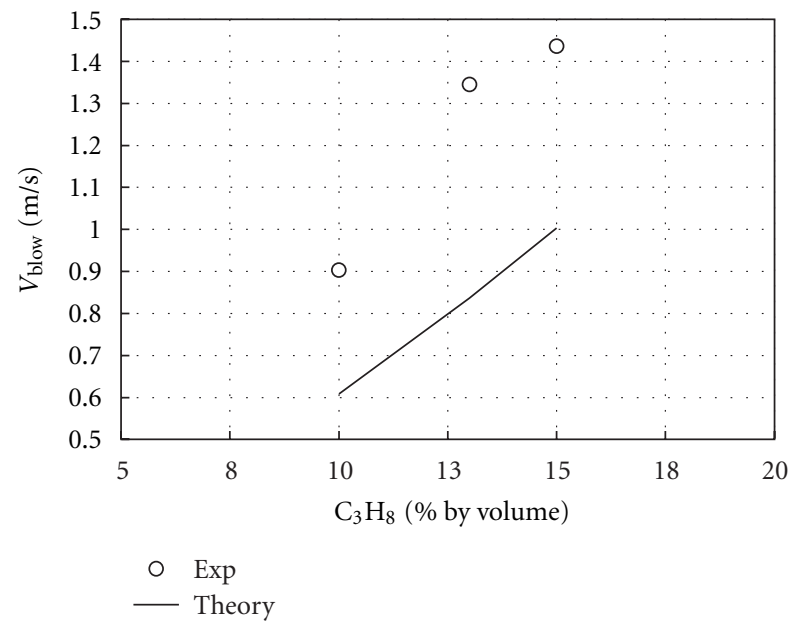

FIGURE 14: Blow-off velocity for nitrogen-diluted mixtures of $\mathrm{C}_{3} \mathrm{H}_{8}$.

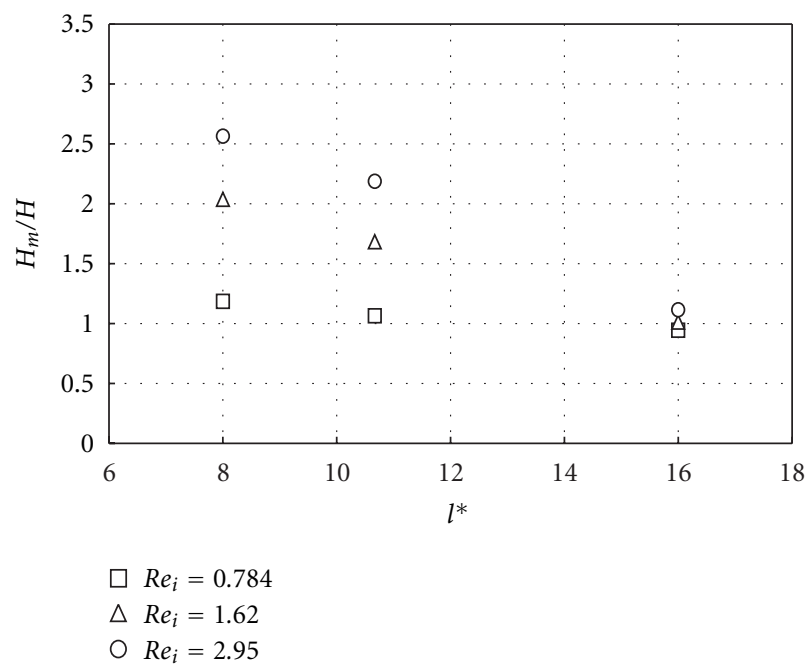

Figure 15: Ratio of multiple flame length to single flame length as a function of interburner spacing and injection velocity for $100 \%$ $\mathrm{CH}_{4}$ fuel.

of the nondimensional interburner spacing $\left(l^{*}=l / d_{i}\right)$ and three injection Reynolds numbers $(0.784,1.62$, and 2.95$)$ for $100 \% \mathrm{CH}_{4}$. It can be deduced from the figure that the strength of multiple flame interaction is governed by two factors: (i) the injection velocity and (ii) the interburner spacing. In general as the interburner spacing is reduced below a certain value, the flames will lengthen due to oxygen deficiency developing in the interstitial space between the flames. However, the magnitude of this increase appears to be governed by the injection $R e_{i}$ (i.e., injection of more fuel). As long as $R e_{i}$ is kept low, the spacing at which interaction will occur can be greatly reduced. In other words, if the injection velocity is kept low, the interactive effects will not be felt until the burners are brought much closer together and even at this lower spacing the interactive effects appear to be weaker. Notice that at $l^{*}=8$ diameters, $H_{m} / H=1.18$ and 2.56 for $R e_{i}=0.784$ and $R e_{i}=2.95$, respectively. On the other hand, if the injection velocity is high, the interactive effects will come in to play at a much earlier spacing and the interactive effects appear to be much stronger. The upper limit on $H_{m} / H$ can be found by recalling that sheath flames behave much like single flames issuing from an equivalent diameter with equal injection velocity. Hence, $d_{i, \text { equiv,sheath }}=3 d_{i}$ for a $2 \mathrm{D}$ jet and $R e_{i \text {,equiv,sheath }}=3 R e_{i}$. Since $H \propto R e_{i}$ as shown in row 17 from Table $1, H_{\text {sheath }} / H_{\text {iso }}=3$. This gives the upper limit on $H_{m} / H_{\text {iso }}$. In other words, if $H_{m} / H_{\text {iso }}=3$, then a sheath flame has formed and the $H_{m} / H_{\text {iso }}$ ratio is at a maximum. Figure 15 shows that the measured $H_{m} / H$ ratios approach the sheath limit.

7.2.2. Multiple-Flame Growth versus Single Flame Growth: Fixed Reynolds Number, Decreased Spacing. As previously mentioned, as the interburner spacing decreases, the flames must widen and lengthen to obtain the necessary oxygen for combustion. This effect was qualitatively illustrated in Figure 8 which identified the stages of interaction as isolated, individual, group, and sheath flames. Now, Figure 16 shows the actual flames undergoing similar stages of interaction. The figure depicts a grouping of three $2 \mathrm{D}$ burners at a fixed injection $R e$ of 3.70 at interburner spacings of 32 burner diameters (Figure 16(a)), 16 burner diameters (Figure 16(b)), 14.4 burner diameters (Figure 16(c)), 13.12 burner diameters (Figure 16(d)) and 9.92 burner diameters (Figure 16(e)). Notice that as the interburner spacing is reduced from 32 to 16 burner diameters, the visible flame heights and the flame characteristics (width, axial location at maximum width etc.) change very little, indicating almost no interaction. Figures 16(a) and 16(b) show the flames in the isolated flame mode. As the spacing is reduced to 14.4 burner diameters, however, the flames begin to interact as evidenced by the flames widening and lengthening slightly. Note that injection velocity in each frame is remaining constant. Therefore, any changes in the characteristics of the flames are due to interactive effects. Even though the flames are interacting in Figure 16(c), as evidenced by increased width and height, they still retain their individual shape. Therefore, these flames are referred to as "individual" in analogy with group combustion literature $[14,16]$. As the spacing is reduced further down to 13.12 burner diameters, the "individual" flame characteristics begin to become lost and the flames begin to start merging together or forming an incipient group flame. At 9.92 burner diameters, the group flame has become a sheath flame meaning that the amount of air entrained in the interstitial space between the burners has fallen to such a low that no flame can exist between the burners, and all of the required air is coming from the ambient surroundings. The flame in Figure 16(d) is similar to a single flame issuing from a larger diameter with a similar throughput. Also note that as the burner spacing is reduced Figures 16(a)-16(d) the fraction of the yellow or sooty region of the visible flame height is increased. This is due to the lack of oxygen in the interstitial space and will mostly likely lead to increased soot and $\mathrm{CO}$ production which could further complicate the interaction process by increasing radiation heat transfer to adjacent flames. The sooty flames are more 


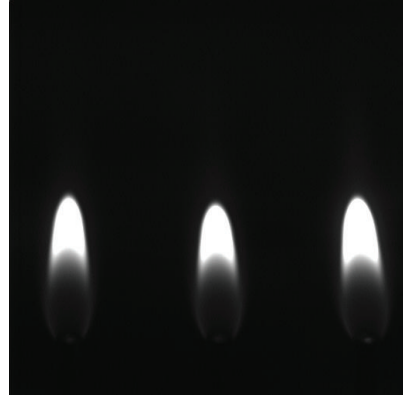

(a)

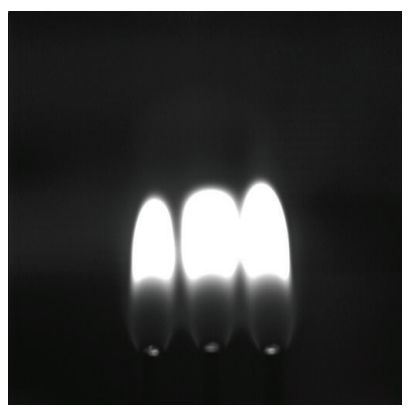

(d)

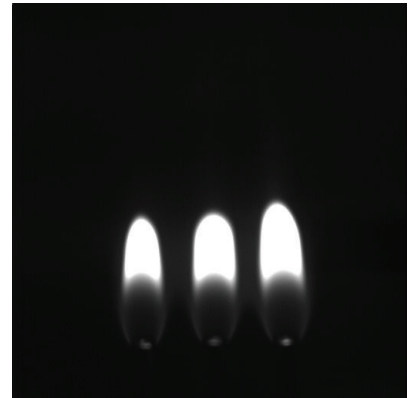

(b)

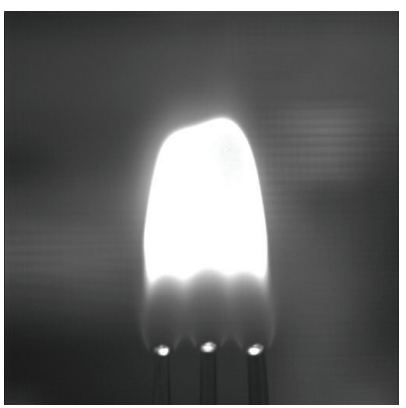

(e)

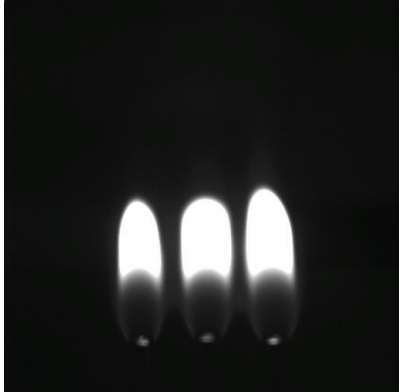

(c)

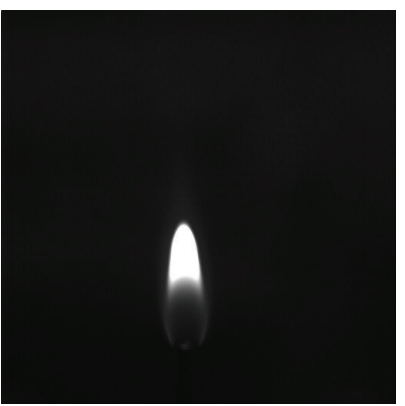

(f)

FIgURE 16: Interaction stages with $R e_{i}=3.70$. (a) Spacing $=32 d_{i}(1 \mathrm{in})$, isolated flame, (b) spacing $=16 d_{i}(0.5$ in), individual flame with weak interaction; (c) spacing $=14.4 d_{i}(0.45 \mathrm{in})$, individual flame with stronger interaction; (d) spacing $=13.12 d_{i}(0.41$ in), incipient group flame; (e) spacing $=9.92 d_{i}\left(0.31\right.$ in), sheath flame, and (f) individual flame with $R e_{i}=1.62$.

luminous and as such the light is reflected back towards the burners, thus illuminating the burner tips as can be seen in various degrees from Figure 16(a) (almost no light reflection to the burner tips) to Figure 16(b) (tips clearly illuminated). To compare the height of a single flame when compared to multiple flames, Figure 16(f) shows the image of multiple flames at a burner spacing of 16 diameters and Reynolds number of 1.62. The multiple flames widened and lengthened due to an oxygen deficiency within the interburner spacing and the location where the maximum width occurs has shifted slightly toward the burner base. This trend becomes more apparent when the Reynolds number is further increased to 5.28 .

\subsection{Criteria for Flame Interaction, Group Flame Formation,} and Sheath Flame Formation. Figure 17 gives the interburner spacing and injection $R e_{i}$ required for flame interaction to begin, group flames to form, and sheath flames to form for a linear array of $2 \mathrm{D}$ burners fired with $100 \% \mathrm{CH}_{4}$. As shown in the figure, isolated flames (as shown in Figure 8(a)) exist for large interburner spacings and low injection Re. At large spacings and low flow rates, the flames have ample oxygen available in the interstitial space and therefore are not affected by the presence of the other burners. As the interburner spacing is decreased and the injection $R e_{i}$ is increased, the flames will begin to interact. The solid line giving interaction criteria was determined by finding the interburner spacing and $R e_{i}$ combinations which gave a $10 \%$ increase in visible flame height $\left(H_{m} / H=1.10\right)$.
Individual flames (as shown in Figure 8(b)), where the flames have not merged together but where interactive effects between the burners increase flame height, flame width, and flame stability exist in the band given between the interaction criteria and group flame formation criteria. Therefore, individual flames exist at higher injection $R e_{i}$ and lower interburner spacings than isolated flames as explained in Figure 8. As the interburner spacing is reduced further and as the injection $R e_{i}$ is increased further, the flames merge together and form a larger group flame as illustrated in Figure 8(c). Group flames exist until the oxygen in the interstitial space falls to approximately zero and a sheath flame forms. The sheath flame (as illustrated in Figures 8(d) and 16(e)) behaves in a similar manner as an isolated flame issuing from a larger burner diameter. For Figure 17, a sheath flame was taken to exist if the merging height for the flames $\left(x_{u}\right.$ in Figure $\left.8(\mathrm{c})\right)$ was less than $2.5 \mathrm{~mm}$. It must also be stated that the interaction criteria, group flame formation and sheath flame formation curves are upward sloping and could be approaching limiting values. For example, the slope of the group flame formation curves grows increasingly larger as the interburner spacing is increased. In other words, the injection $R e_{i}$ at an interburner spacing of 20 to 25 burner diameters may approach infinity, making forming a group flame impossible beyond certain spacing. The same may be true for interaction criteria and sheath flame formation criteria. In fact, it is expected that the sheath flame formation criteria would be the steepest curve followed by the group flame formation curve and the interaction curve. 


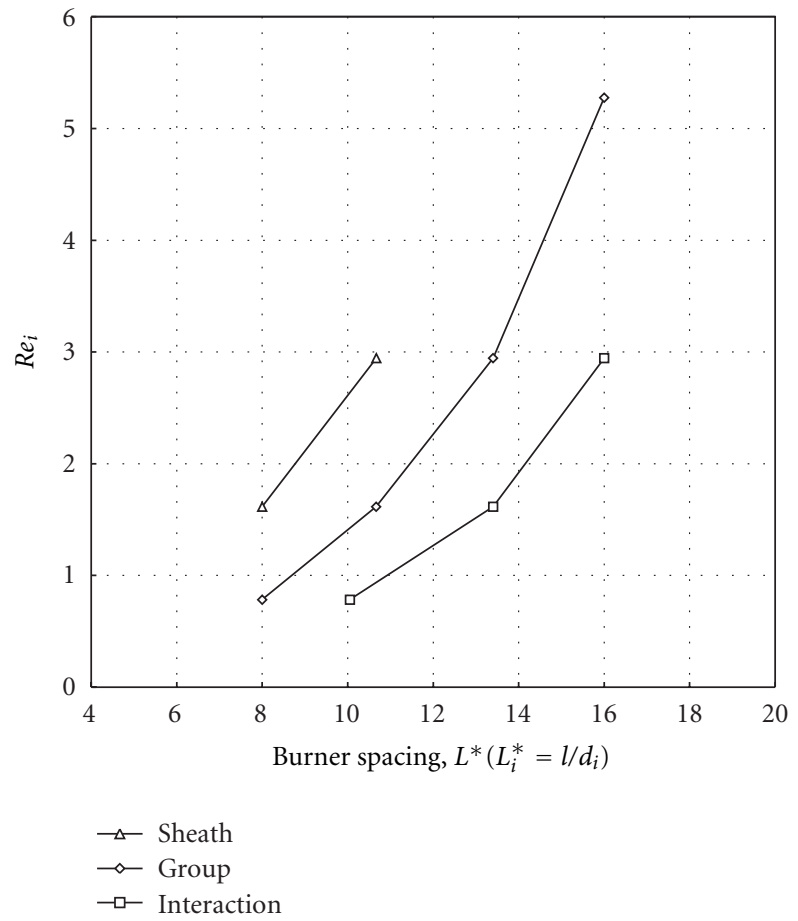

FIGURE 17: Interburner spacing required for flame interaction and group flame formation as a function of injection velocity for $100 \%$ $\mathrm{CH}_{4}$ fuel.

7.3.1. Interaction Criteria: Comparison with Theory. Figure 18 gives the comparison between the experimentally observed interactions (shown in Figure 17) and the theoretical predictions for flame interaction and group flame formation (equations (16b) and (21c)) for a linear array of $2 \mathrm{D}$ burners fired with $100 \% \mathrm{CH}_{4}$. Here, the interburner spacing, $l$, has been nondimensionalized by the isolated visible flame height $(H)$, which was measured for a single $2 \mathrm{D}$ jet. $R e_{i}$ of the single jet was kept the same as the $R e_{i}$ per burner for the linear array of $2 \mathrm{D}$ jets. In Figure 18, the dashed line corresponds to theoretical predictions for flame interaction based on the adjacent mixing layers intersecting at the isolated flame height (shown in Figure 8(a)) as given by $(15 \mathrm{~d})$. The dotted line corresponds to the theoretical prediction for group flame formation assuming that there is insufficient air available in the interstitial space between the flames as found in (21c). The solid line gives the group flame formation prediction based on isolated flames touching at their maximum width as given in (16b). As shown in the figure, equations (15d) and (21c) overpredict the interburner spacing necessary to form individual and group flames, respectively, by approximately a factor of 4 . Comparison between the theoretical predictions for group flame formation given by (16b) and the experimental measurements for group flame formation, represented by the square data points in the figure, is good. This comparison is better at higher $R e_{i}$ as buoyancy forces, which were neglected from our analysis, decrease to smaller value. Froude numbers, as defined in row 2 , were calculated to be a maximum of 0.56 at $R e_{i}=6.86$ and $l^{*}=64$ and a minimum of 0.154 at $R e_{i}=0.78$ and $l^{*}=8$.

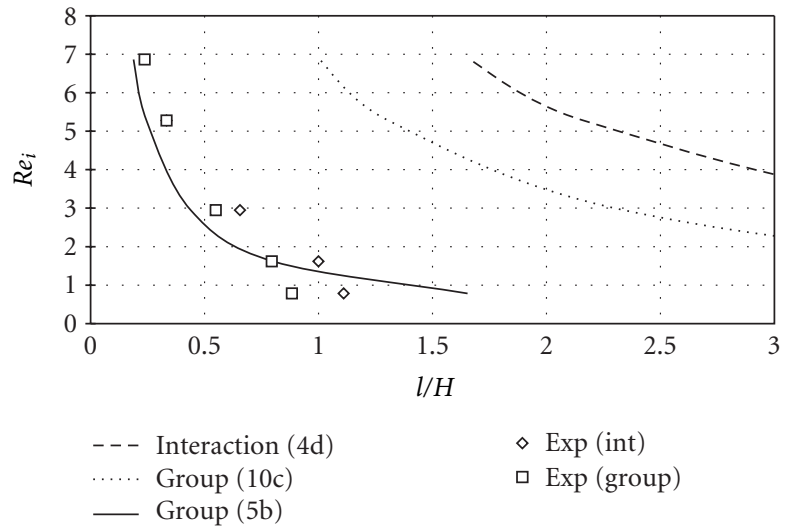

FIGURE 18: Comparison of theoretical predictions (given in (4d), (5b), and (10c)) and experimentally observed interburner spacing nondimensionalized by the visible flame height of a single isolated jet for $\mathrm{CH}_{4}$ fuel.

\subsection{Interactive Effects on Flame Geometry: Comparison with Theory}

7.4.1. Schlieren Images of $2 D$ Jets. A Schlieren system was used to study the interaction of multiple flames at various interburner spacings. Figure 19 shows the captured Schlieren images for a linear array of three 2D jets at interburner spacings of 64,32 , and 16 burner diameters. In each frame, the burners have been fired with $14.8 \mathrm{~mL} / \mathrm{min} /$ burner of $\mathrm{C}_{3} \mathrm{H}_{8}\left(R e_{i}=2.97\right)$, therefore, any changes in the images will be due strictly due to interactive processes between the flames. As shown in Figure 19, there is a vast difference in the images. In Figure 19(a), the burners are separated by 64 burner widths (approximately $54.8 \mathrm{~mm}$ ). At this spacing, the first order density gradients of each flame $(\partial \rho / \partial y=$ $\left.-\left(P / \mathrm{RT}^{2}\right) \partial T / \partial y\right)$ do not intersect and the flames are operating under "isolated" conditions. As the spacing is reduced to 32 burner widths (approximately $25.4 \mathrm{~mm}$ ) as shown in Figure 19(b), the density gradients intersect at some axial distance away from the burner (typically beyond the flame tips). It appears that the density gradient growth (width, etc.) from Figures 19 (a) to 19(b) remains unchanged. The intersection of the density gradients as shown in Figure 19(b) may be a sign of flame interaction but definitely does not represent the merging of flames. Interestingly enough, changes in the flame structure and flame stability were not noticed until a much closer spacing, namely, 16 burner diameters or $12.7 \mathrm{~mm}$ spacing. This means that the intersection of the first order density gradient may have little effect on the visible characteristics of the flames.

As the spacing is reduced to 16 burner widths $(12.7 \mathrm{~mm})$ as shown in Figure 19(c), a very interesting phenomenon occurs. The flames begin to flicker or pulse in series at a frequency of approximately $10 \mathrm{~Hz}$. It should be noted that this flickering was not observed until the spacing was decreased to 16 burner widths. It is therefore believed that this flickering is a direct result of the interaction between the flames. It should also be noted that the flickering ceases if one of the outside burners is removed (e.g., in the row of a binary 


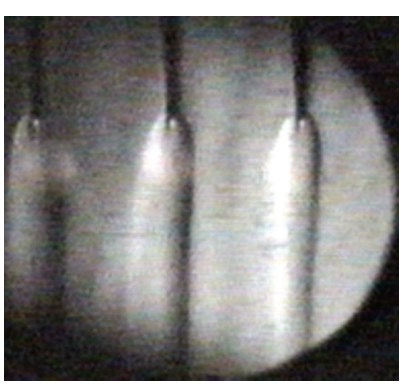

(a)

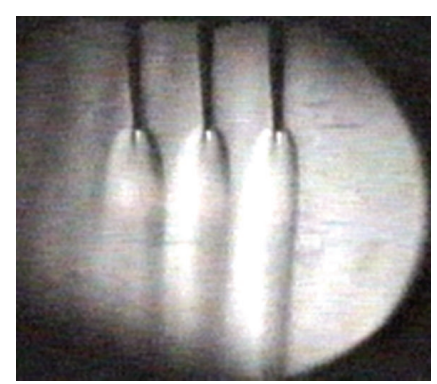

(b)

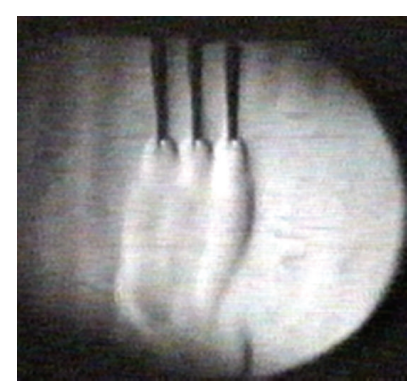

(c)

FIgURE 19: Sequence of Schlieren images for $14.8 \mathrm{~mL} / \mathrm{min} /$ burner of $\mathrm{C}_{3} \mathrm{H}_{8}\left(R e_{i}=2.97\right)$ : (a) 64 burner widths (2 in), (b) 32 burner widths ( 1 in), and (c) 16 burner widths ( 0.5 in).

array at the same $R e_{i}$, the flickering ceases). One possible explanation for the flickering observed in the triple burner array can be found by analyzing the flame height expression from row 17 . The flame height of a $2 \mathrm{D}$ jet is a very strong function of oxygen concentration (given by the $1 / \phi_{f}^{3}$ term in row 17). Hence, a small decrease in oxygen concentration will result in a large increase in flame height. It is possible that as the flames are brought within 16 burner widths of one another, oxygen concentration in the interstitial space around the central flame decreases. If disturbances in the oxygen concentration occur, then $Y_{\mathrm{O}_{2}, \infty}=Y_{\mathrm{O}_{2}, \infty \text {,avg }}+\varepsilon$. If $\varepsilon<0$, then the oxygen concentration decreases and the flame lengthens. Once the flame lengthens, oxygen consumption decreases since the injected fuel is being consumed over a larger axial distance. This decreased consumption rate of oxygen could cause the oxygen concentration in the interstitial space to rise again $(\varepsilon>0)$, lowering the flame height. So it is possible that the flickering can be attributed to disturbances in the levels of oxygen concentration available for the central flame.

\subsection{Interactive Effects on Flame Stability: Comparison with Theory}

7.5.1. Lift-Off Measurements with Nitrogen-Diluted $\mathrm{C}_{3} \mathrm{H}_{8}$ Mixtures. Since no lift-off was observed for $\mathrm{CH}_{4}(\mathrm{Sc}<$ 1) flames, the $2 \mathrm{D}$ jets were fired with a Nitrogen-diluted mixture of Propane $(S c>1)$. The lift-off height to flame height ratio for an $85 \% \mathrm{~N}_{2}-15 \% \mathrm{C}_{3} \mathrm{H}_{8}$ mixture is shown in Figure 20 for interburner spacings of 64, 16, and 10.67 widths. The percentage of Nitrogen dilution was selected to allow blow-off to occur in the laminar regime. As shown in the figure (solid line) and given in the theory (row 24), $\left.L / H \propto v_{x, i}^{(3 S c / S c-1)}\right)$, lift-off height increases as the injection velocity is increased. Schmidt number for the fuel mixture (used in row 23) was taken to be 1.30 based on a stoichiometric mixture of $\mathrm{C}_{3} \mathrm{H}_{8}$ and air. $M^{*}$ in row 23 was selected to be 1.2 representing nonbuoyant conditions and the laminar flame speed was taken to be $0.25 \mathrm{~m} / \mathrm{s}$ based on experimental measurements [6]. The isolated flame theory tends to predict lift-off at a later injection velocity than the experiment and also shows a steeper increase in lift-off height. The theory also predicts a lower blow-off

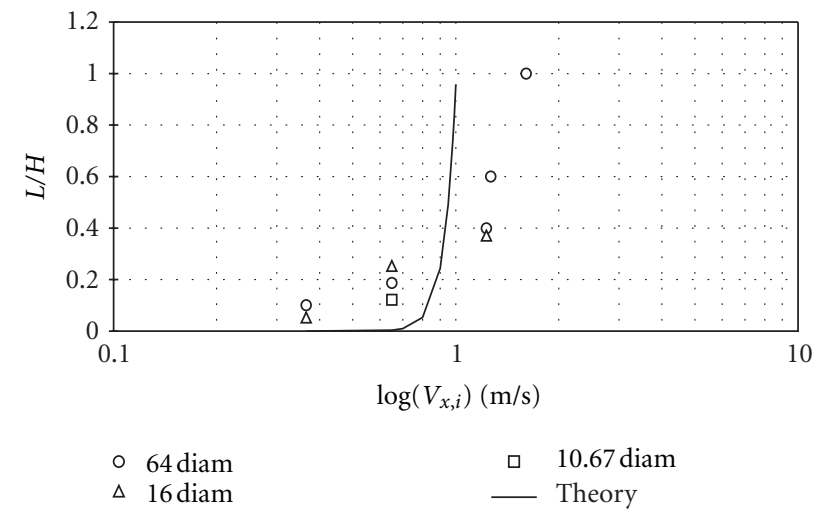

Figure 20: Lift-off height for $85 \% \mathrm{~N}_{2}$ and $13 \% \mathrm{C}_{3} \mathrm{H}_{8}$ mixture.

velocity than the experiment, given by $L / H=1$. Also, the experimental data shown in Figure 20 seems to suggest that $L / H$ decreases for a given injection velocity as the separation distance between the burners is decreased. From the experimental data it appears that increases in flame height may be larger than increases in lift-off height.

7.5.2. Blow-Off for Nitrogen-Diluted $\mathrm{C}_{3} \mathrm{H}_{8}$ Mixture $(\mathrm{Sc}>1)$. Comparison between the laminar flame theory's prediction of blow-off velocity (as given in row 24) and the experimental measurements of blow-off in a linear array of three planar burners fired with $\mathrm{N}_{2}$-diluted mixtures of $\mathrm{C}_{3} \mathrm{H}_{8}$ is given in Figure 21. For the theoretical predictions of blow-off for an isolated flame, $M^{*}$ and $J^{*}$ were selected to be 1.2 and 1.0 , respectively. $S$ was taken to be $0.2,0.23$, and $0.25 \mathrm{~m} / \mathrm{s}$ for $90 \% \mathrm{~N}_{2}-10 \% \mathrm{C}_{3} \mathrm{H}_{8}, 87 \% \mathrm{~N}_{2}-13 \% \mathrm{C}_{3} \mathrm{H}_{8}$, and $85 \% \mathrm{~N}_{2}-$ $15 \% \mathrm{C}_{3} \mathrm{H}_{8}$ mixtures from experimental data collected, [6] respectively. As shown in the figure, there is no change in blow -off velocity for interburner spacing of 64 and 16 burners diameters and the theory underpredicts the blow-off velocity at these spacings by a factor of about 1.40 . However, as the interburner spacing is reduced to 10.67 diameters, there is a large increase in blow-off velocity marking an approximately 50\% increase in flame stability. Even though isolated flame theory underpredicts the experimental data, it is encouraging that the theory shows the same trends 


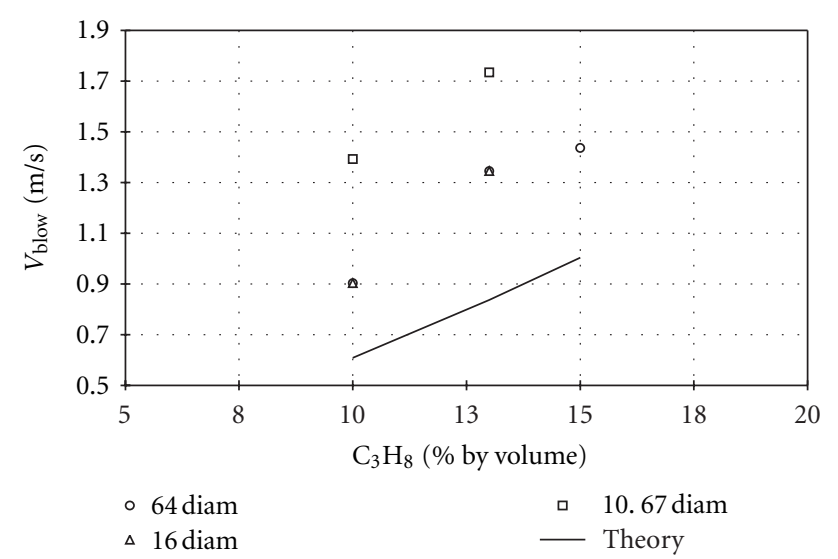

Figure 21: Blow-off velocity for nitrogen-diluted mixtures of $\mathrm{C}_{3} \mathrm{H}_{8}$.

as experiments. As the mixture is leaned, both theory and experiment show a similar decrease in blow-off velocity.

\section{Conclusions}

\subsection{Isolated Jets}

(1) Solutions for the compressible form of the governing equations of mass, momentum, energy, and species for a single $2 \mathrm{D}$ jet were solved to give explicit solutions for flame height and width, mixing layer growth, lift-off height, and blow-off velocity.

(2) A flame stability theory (lift-off, blow-off velocity, etc.) was offered based on two important parameters: the flame speed contour, giving the positions in space where the axial gas velocity equals the laminar flame speed and the stoichiometric contour giving the positions in space where fuel and air are in stoichiometric proportions. For fuels with $S c=1$, if the stoichiometric contour lies "inside" the flame speed contour, a stable flame is predicted. If the stoichiometric contour lies "outside" the flame speed contour, blow-off is achieved. If the two contours intersect $(S c \neq 1)$, the intersection point corresponds to the lift-off height $(S c>1)$ or the ignitable or possibly partial flame height $(S c<1)$.

(3) Schmidt number was found to play a key role in flame stabilization processes. For $S c=1$, no intersection between the flame speed and stoichiometric contours is possible and hence no lifted flames are predicted. For $S c>1$, the intersection of the contours gave the lift-off height which increased with increasing Reynolds number until the blow-off condition was reached. For $S c<1$, an interesting scenario was observed. The intersection of the contours leads to an ignitable height or partial flame height which decreased as Reynolds number was increased.

(4) Laminar flame theory predictions compared favorably with experimental data collected for a single 2D jet.

\subsection{Triple Burner Jets}

(1) Laminar single flame theory was modified to include multiple burner effects to obtain simple expressions which predict the interburner spacing at which flame interaction begins and at which formation of group flames occurs.

(2) Four distinctive modes of flame interaction were identified: (a) isolated, (b) individual, (c) group, and (d) sheath. For a given burner geometry and combustible fuel properties, these modes were found to be a function of interburner spacing and injection Reynolds number.

(3) At low injection Reynolds numbers, flame interaction can cause flame flicker.

(4) Laminar isolated flame theory underpredicts the blow-off velocity in linear arrays of 2D burners by approximately $40 \%$ for interburner spacings from 64 to 16 burner widths.

\section{Acknowledgments}

The authors wish to acknowledge the partial financial support provided for this research by the Energy Resources Program of the State of Texas and Paul Pepper Professorship to one of the authors. The authors appreciate the assistance with the Schlieren imaging system provided by Prof. K. Kihm of Texas A\&M University and the time and effort dedicated to the project by Daniel Snook of Auburn University.

\section{References}

[1] L. Van quickenborne and A. Van Tiggelen, "The stabilization mechanism of lifted diffusion flames," Combustion and Flame, vol. 10, no. 1, pp. 59-69, 1966.

[2] G. T. Kalghatgi, "Blow-out stability of gaseous jet diffusion flames. Part I: in still air," Combustion Science and Technology, vol. 26, no. 5-6, pp. 233-239, 1981.

[3] S. H. Chung and B. J. Lee, "On the characteristics of laminar lifted flames in a nonpremixed jet," Combustion and Flame, vol. 86, no. 1-2, pp. 62-72, 1991.

[4] R. Menon and S. R. Gollahalli, "Combustion characteristics of interacting multiple jets in cross flow," Combustion Science and Technology, vol. 60, no. 4-6, pp. 375-389, 1988.

[5] A. A. Putnam and C. F. Speich, "A model study of the interaction of multiple turbulent diffusion flames," Symposium (International) on Combustion, vol. 9, no. 1, pp. 867-877, 1963.

[6] B. Lenze, M. E. Milano, and R. Guenther, "The mutual influence of multiple jet diffusion flames," Combustion Science and Technology, vol. 11, no. 1-2, pp. 1-8, 1975.

[7] R. Menon and S. R. Gollahalli, "Multiple jet gas flames in still air," in Heat Transfer and Fire and Combustion Systems, vol. 45 of HTD, pp. 127-136, American Society of Mechanical Engineers, 1985.

[8] K. Annamalai and M. Sibulkin, "Flame spread over combustible surfaces for laminar flow systems. Part I: excess fuel and heat flux," Combustion Science and Technology, vol. 19, no. 5-6, pp. 167-183, 1979. 
[9] K. Annamalai and T. Tillman, "Mixing, stability, and combustion of 2D and circular laminar jets," Report CF-98-1, Combustion LaboratoryTexas A\&M University, 1998.

[10] K. Annamali and K. Puri, Combustion Science and Engineering, Taylor \& Francis Group, 2007.

[11] H. Schlicting, Boundary Layer Theory, McGraw-Hill, 1955.

[12] J. A. Fay, "The distribution of concentration and temperature in a laminar jet diffusion flame," Journal of Aeronautical Sciences, vol. 21, pp. 681-689, 1954.

[13] S. T. Tillman, Lift-off and blow-off in gas fired cluster burners [Ph.D. thesis], Texas A\&M University, College Station, 2000.

[14] S. T. Tillman, K. Annamalai, and J. A. Caton, "Effect of interaction on liftoff of non-premixed circular jets," in Proceedings of the Combustion Institute/Central States Section Meeting, Point Clear, Ala, USA, April 1997.

[15] V. Siwatch, Modeling of Formation in Circular Laminar Jet Flames [M.S. thesis], Mechanical Engineering, Texas A\&M University, 2005.

[16] H. H. Chiu and T. M. Liu, "Interactive processes in gasification and combustion. Part I: liquid drop arrays and clouds," Combustion Science and Technology, vol. 17, no. 3-4, pp. 127$142,1977$.

[17] K. Annamalai and W. Ryan, "Interactive processes in gasification and combustion. Part I: liquid drop arrays and clouds," Progress in Energy and Combustion Science, vol. 18, no. 3, pp. 221-295, 1992.

[18] R. Menon and S. R. Gollahalli, "Characteristics of interacting multiple jets," Combustion Science and Technology, vol. 60, no. 4-6, pp. 375-389, 1988.

[19] B. Lewis and G. von Elbe, Combustion, Flames, and Explosions of Gases, Academic Press, 3rd edition, 1987.

[20] C. Womeldorf and W. Grosshandler, "Flame extinction limits in $\mathrm{CH}_{2} \mathrm{~F}_{2}$ /air mixtures," Combustion and Flame, vol. 118, no. 1-2, pp. 25-36, 1999.

[21] K. Annamalai, W. Ryan, and S. Dhanapalan, "Interactive processes in gasification and combustion-Part III: coal/char particle arrays, streams and clouds," Progress in Energy and Combustion Science, vol. 20, no. 6, pp. 487-618, 1994. 

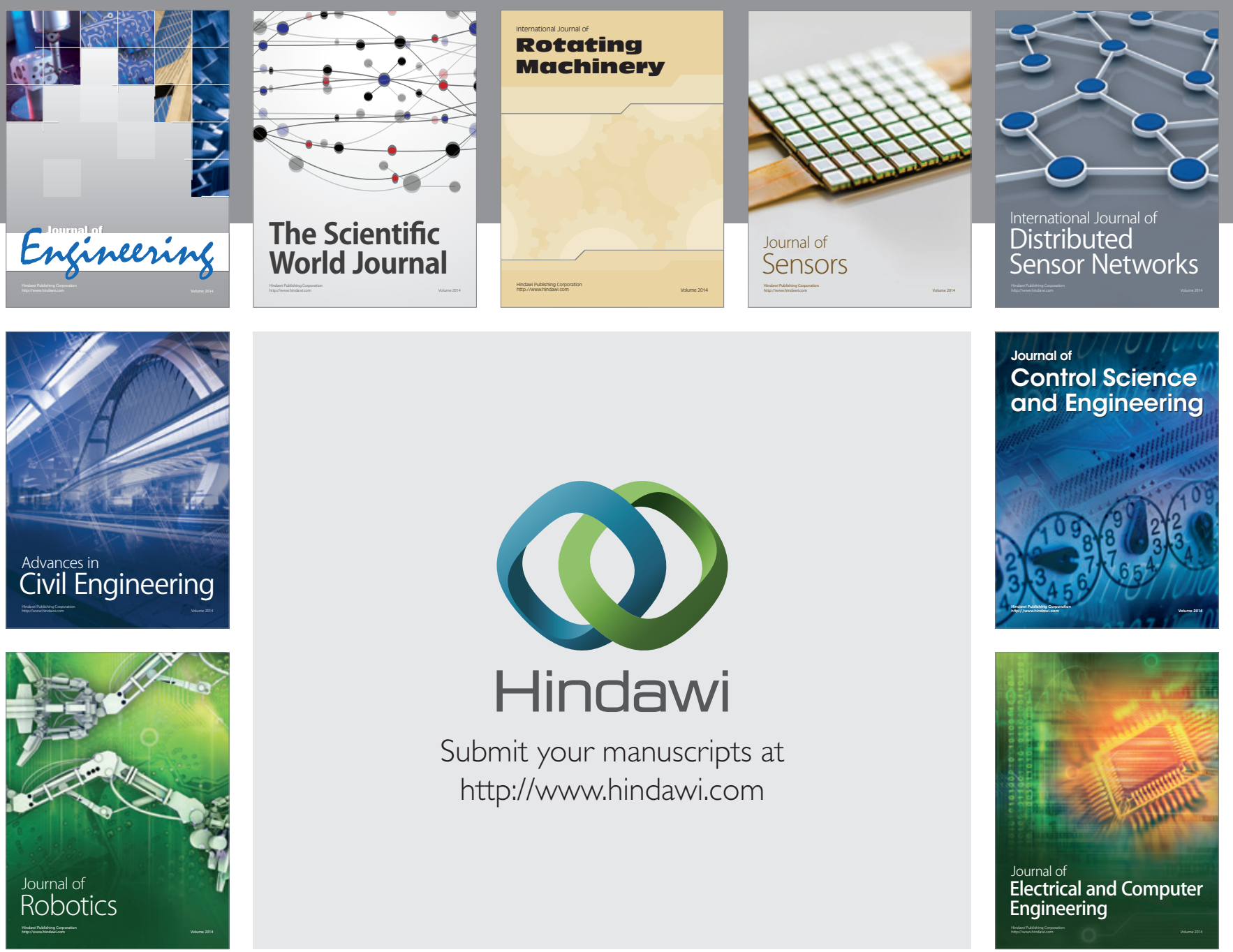

Submit your manuscripts at

http://www.hindawi.com
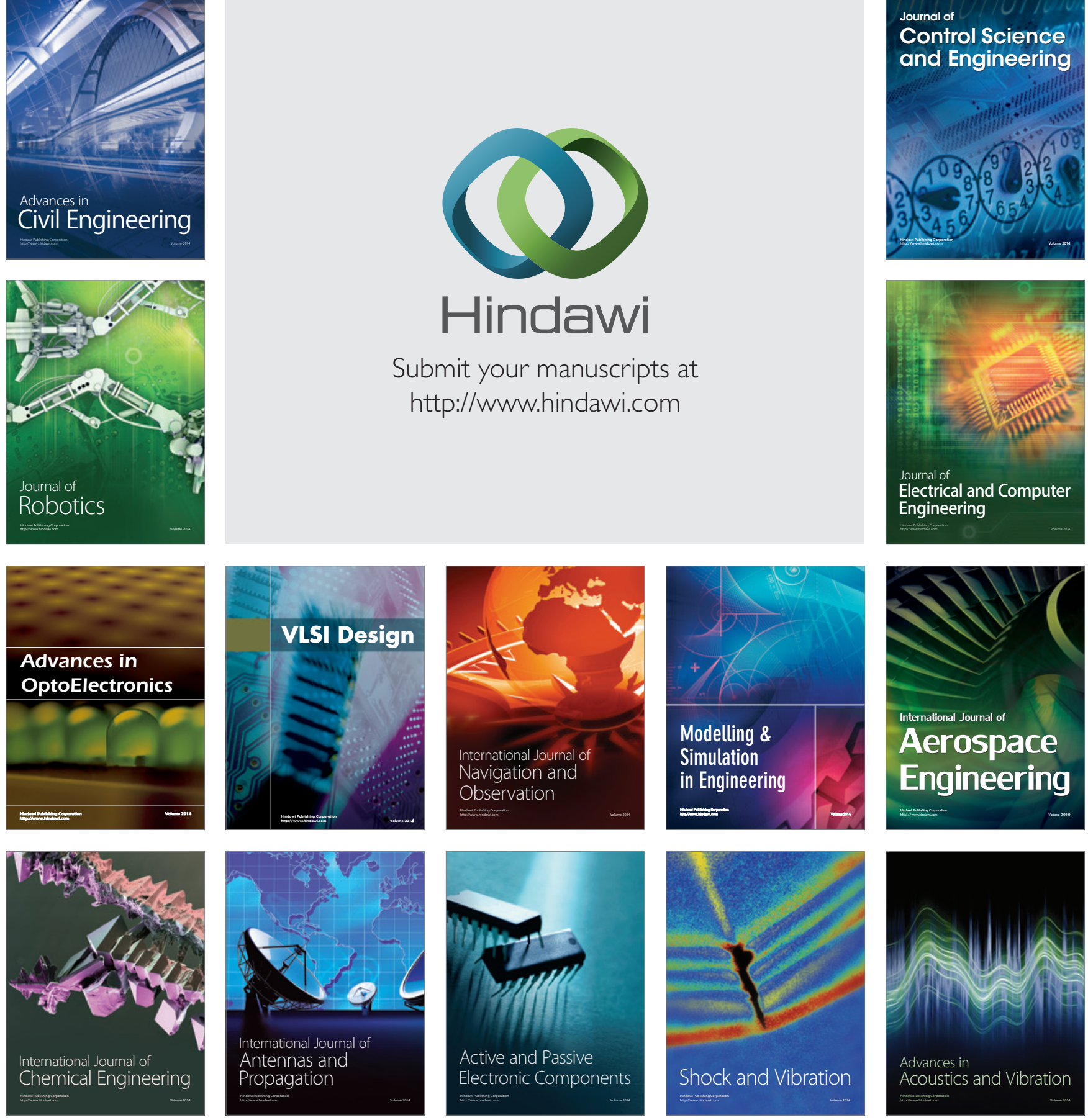